\title{
In situ Formation of Metal Nanoparticles through Electron Beam Irradiation: Modeling Real Materials from First-Principles Calculations
}

Juan Andrés ${ }^{1 *}$, Elson Longo ${ }^{2 *}$, Amanda F Gouveia ${ }^{2}$, João PC Costa ${ }^{2}$, Lourdes Gracia ${ }^{3}$ and Marisa C Oliveira ${ }^{1}$

${ }^{1}$ Department of Analytical and Physical Chemistry, University Jaume I (UJI), Castelló 12071, Spain

${ }^{2}$ CDMF, Universidade Federal de São Carlos, P.O. Box 676, CEP, 13565-905, São Carlos-SP, Brazil

${ }^{3}$ Department of Physical Chemistry, University of Valencia, Burjassot E-46100, Spain

\begin{abstract}
Advances in electron-matter studies, based on the irradiation of the electron beam in the transmission electron microscopy or field emission-scanning electron microscope on materials represents a preferred external physical and chemical tool for in situ remote command of the functional attributes of nanomaterials associated to its unique advantages of high spatial and temporal resolution and digital controllability. This makes the field of electron beam irradiation an emerging topic open for many researchers right now. Electron-material interactions envisage the formation, growth and coalescence of metal nanoparticles induced by electron beam irradiations and motivated by this discovery, in this Review, we provide an account of the recent advancements and theoretical developments to describe this phenomena and their applications. A theoretical framework is developed to determine the physical principles involved in the mechanism for the formation of metal nanoparticles on different materials by electron beam irradiation under the guidance of first-principles calculations at density functional level. New research directions are emerging in materials science to reach many applications by providing a deeper insight in the properties and phenomena in complex material systems. We conclude our work by briefly outlining the challenges that need to be addressed and the opportunities that can be tapped into. We hope that the review of the flourishing and vibrant topic with myriad possibilities would shine light on exploring the future directions of this research field by encouraging and opening the windows to meaningful multidisciplinary cooperation of researchers from different backgrounds and scientists from the fields such as chemistry, physics, engineering, biology, nanotechnology and materials science.
\end{abstract}

Keywords: Electron beam; TEM; FE-SEM; First-principles calculations

\section{Introduction}

Theory of electron-solid interactions is necessary for many material analysis techniques such as electron spectroscopy, diffraction, and microscopy. These techniques have completely revolutionized many disciplines of natural sciences and are becoming some of the best solutions for material exploration, elucidation, and characterization. In the development of electron microscopy, electron-matter interaction has been one of the key discussion topics.

Transmission electron microscopy (TEM) and field emissionscanning electron microscopy (FE-SEM) are some of the important tools for investigating the morphology of materials, from sub-nanometer to micrometer length scales. In particular, the development of electron microscopy, which involves the electron beam-matter interaction and is an interactional typical quantum phenomenon, has been one of the key areas of modern science. The electrons in solids face two forces: a Coulombic interaction force between themselves, and a force from the atomic nuclei. Electrons and/or photons interact with the atoms, molecules, and solids at the quantum level. However, predicting the response of a material to the passage of electrons and waves is very challenging. Indeed, the ability to control the structure of matter at the molecular level, i.e., at the cluster or nanoscale, together with the development of new concepts and tools (for example, spectroscopy and microscopy pushed to an extreme resolution in time and space), can lead to new and unconventional scenarios for light-matter or electronmatter interactions. In particular, the quantum description of electrons, as Fermion particles, is governed by the Pauli's exclusion principle, and their distribution in position or momentum space represents a fundamental property in the fields of chemistry and physics and is at the heart of all reaction processes and molecular functionalities.

Useful insights have been obtained from the existing knowledge of electron beam (e-beam) interactions with solid matter [1]. In
TEM, a high-energy e-beam is passed through the sample to be imaged, which allows an image to be formed as in a conventional light microscope owing to the use of the quantum mechanical wave nature of electrons [2]. Therefore, the TEM is a fundamental technique to observe the microstructure, characterize nanoscale materials, and provide chemical information on an atomic scale. It is also well known that the high energy of the e-beam used in TEM can cause radiation damage in the materials being probed and sometimes leads to certain in situ transformations that are accelerated by the damage process $[1,3]$. The increase in the electron energy leads to bond instability and consequently the change in the structure $[1,4]$. Such structural defects not only deteriorate the physical and chemical properties, but also cause a failure in the subsequent application [5].

The conventional microstructure characterization of nanomaterials relies heavily on the TEM or FE-SEM by providing atomic-resolution images and has become a very cogent way to investigate the structure and properties of the nanostructures, endowing the researcher both in situ nanomanipulation and in situ imaging at the same time [610]. Applying the e-beam irradiation inside the TEM or FE-SEM as an external stimulus, which allows high-energy electrons to transmit through the specimen, provides useful microstructure and

*Corresponding author: Juan Andreas, Department of Analytical and Physical Chemistry, University Jaume I (UJI), Castelló 12071, Spain, Tel: +34 964728 083; E-mail: andres@qfa.uji.es

Received May 21, 2018; Accepted June 18, 2018; Published June 28, 2018

Citation: Andrés J, Longo E, Gouveia AF, Costa JPC, Gracia L, et al. (2018) In situ Formation of Metal Nanoparticles through Electron Beam Irradiation: Modeling Real Materials from First-Principles Calculations. J Material Sci Eng 7: 461. doi: 10.4172/2169-0022.1000461

Copyright: $\odot 2018$ Andrés J, et al. This is an open-access article distributed under the terms of the Creative Commons Attribution License, which permits unrestricted use, distribution, and reproduction in any medium, provided the original author and source are credited. 
electronic structure information of the samples based on a variety of electron-solid interactions [11-13]. This radiation leads to interesting phenomena caused by electron-solid interactions [12-15] and can be as observed while imaging. At this point, it is important to remark that electrons present more advantages than both X-rays and neutrons for investigating the condensed matter, as demonstrated by Henderson in his seminal review [16].

The electron beam generated within the TEM or FE-SEM constitutes a platform for directly imaging metal nanoparticles. They not only offer spectroscopic techniques that prove the presence of individual elements, but also make it possible to do this on a local scale. The e-beam irradiation in TEM can be used for fabricating nanomaterials as well as for investigating the morphology, structure, and chemical transformation of nanomaterials, which are important for developing novel nanostructures, especially for those that cannot be fabricated using conventional chemical and physical methods. Therefore, these new applications have ensured that TEM can be considered as a versatile tool in material engineering at the nanoscale $[17,18]$.

The above processes are triggered by electron beam irradiation, which allows simultaneous fabrication and observation in a convenient and, more importantly, direct manner. Jiang [19] has summarized a variety of beam damage phenomena related to oxides in STEM (scanning TEM) and has underlined the shortcomings of currently popular mechanisms. El Mel and Bittencourt [20] have summarized the solid-to-hollow conversion processes induced by e-beam irradiation in TEM through many important examples reported in the literature. More recently, Gonzalez-Martinez et al. [21] conducted a review aimed at exploring the body of work available on the electron beam induced synthesis techniques with in situ capabilities. A particular emphasis is placed on the e-beam induced synthesis of nanostructures conducted inside the TEM, viz., the e-beam is the sole (or primary) agent triggering and driving the synthesis process.

TEM has been used for etching and patterning a wide range of materials, varying from $\mathrm{Si}$ and metal nanowires [22] to carbon nanotubes [23-25], for reduction of the transition of metal oxide surfaces to metallic lower oxides [26] and graphene [27-29], as well as for in situ growth [30-36] and structural conversion of nanomaterials induced by e-beam [10,37-49]. Recently, Tan et al. [50] have studied the degradation process of closely spaced $\mathrm{Ag}$ and $\mathrm{Au}$ nanocubes under high-energy e-beam irradiation using TEM.

Recent advances in the TEM technology enable studies of atomicscale processes on sub-millisecond time scales [51,52], modification of structural and physical properties of materials for technological applications [14,53-58], nucleation and growth processes of nanocrystals [59,60], catalytically driven reactions [61], changes in the structural and optical properties of nanoparticles [53,55,57], and structural phase transformations $[62,63]$.

In the last few years, it has been demonstrated that the e-beam generated within TEM [2] is a very powerful tool for the fabrication and manipulation of nanostructures with the advantages of precise control at nanoscale or single-nanoparticle level $[17,64,65]$. More recently, Jesse et al. [66] reviewed recent results that used focused electron beam to create free standing nanoscale 3D structures, radiolysis, and fabrication potential with liquid precursors, epitaxial crystallization of amorphous oxides with atomic layer precision, and visualization and control of individual dopant motion within a $3 \mathrm{D}$ crystal lattice. Mansourian et al. [67] have stated the use of the e-beam irradiation to fabricate nanoparticles and nanorods on Ag surfaces with nanometric precision. Both high control over nanorod dimensions and high placement accuracy have been demonstrated.

Yang et al. [68] have developed a method based on the displacement reaction and spontaneous electrolysis to synthesize switching riddle of $\mathrm{Ag}$ tetracyanoquinodimethane (AgTCNQ) nanowires facilely and efficiently in a large area. The authors show that the nanodots and nanoclusters of $\mathrm{Ag}$ begin to precipitate under the irradiation of e-beam. The observed pattern of the separation of the Ag nanoclusters from the AgTCNQ matrix is similar to that of various well-known solid electrolytes such as $\mathrm{Ag}_{2} \mathrm{~S}$ [69], $\mathrm{RbAg}_{4} \mathrm{I}_{5}$ [70], and $\mathrm{Ag}_{2} \mathrm{WO}_{4}$ [71] in electrochemical metallization memories or atomic switches [72-74].

In 2007, Kim et al. [75] obtained Bi nanoparticles by irradiating $\mathrm{BiCl}_{3}$ films by using TEM with a pretreatment involving harsh reaction conditions before the electron irradiation of the sample and a high dose and a high accelerating voltage $(400 \mathrm{kV})$, while Sepulveda-Guzman et al. [76] have also observed in situ formation of Bi nanoparticles through e-beam irradiation of a bismuth precursor $\left(\mathrm{NaBiO}_{3}\right)$ in a TEM without pretreatments and with the use of considerably lower irradiation conditions. These authors have proposed that at the first stage $\mathrm{NaBiO}_{3}$ precursor gets decomposed by a radiolysis process producing $\mathrm{Bi}^{5+}$ ions and neutral $\mathrm{Bi}^{0}$ that segregate and nucleate into small crystalline seeds ( $\mathrm{O}$ and $\mathrm{Na}$ may get volatilized in the process). The seeds then coalesce into larger nanoparticles via Ostwald ripening processes driven by the beam-enhanced diffusion. In recent times, Chang et al. [77] have reported the observation of the formation and growth of $\mathrm{Bi}$ nanoparticles onto $2 \mathrm{D}$ structured $\mathrm{BiOCl}$ photocatalysts by the direct use of TEM in real time (Figure 1). The growth of the Bi nanoparticles on $\mathrm{BiOCl}$ nanosheets can be emulated and speeded up by the use of the e-beam in TEM. The crystallinity growth and the elemental evolution during the formation of $\mathrm{Bi}$ nanoparticles have also been probed in this work.

Gonzalez-Martinez et al. [65] have recently developed an in situ catalyst-free room temperature growth route for crystalline aluminum borate nanowires and nanowires using the e-beam in a TEM. Recently, an increasing number of studies have reported the formation of $\mathrm{Pb}$ nanoparticles upon thee-beam irradiation from TEM on lead halide perovskite: $\mathrm{CH}_{3} \mathrm{NH}_{3} \mathrm{PbX}_{3}[78,79],\left(\mathrm{C}_{4} \mathrm{H}_{9} \mathrm{NH}_{3}\right)_{2} \mathrm{PbBr}_{4}$ [80], and CsPbX [81-86]. There is also evidence that the $\mathrm{Pb}^{2+}$ species from various material systems can be reduced to $\mathrm{Pb}^{0}$ by irradiation with electrons or with X-rays $[87,88]$, while other studies on the irradiation effects in $\mathrm{APbX}_{3}$ nanoparticles have suggested that $\mathrm{PbBr}_{2}$ is also formed [78].

Even in the liquid cells for TEM, many nanoscale crystallization and nanoparticle growth processes have only been observed in the presence of the beam $[25,59,89-93]$. In addition to the solid-phase transitions,

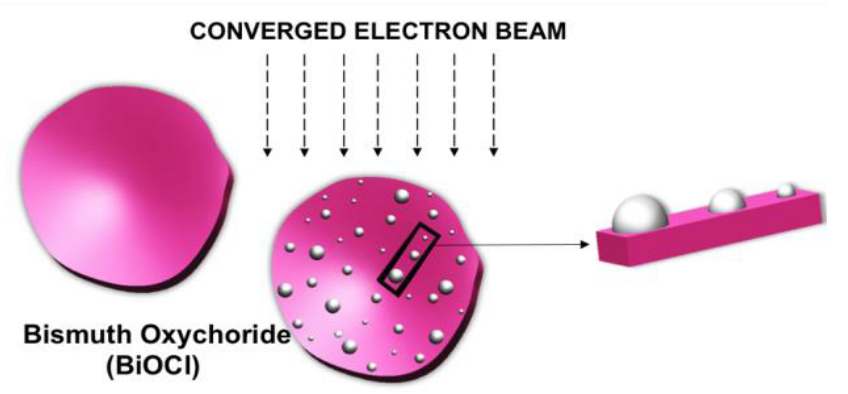

Figure 1: Representative scheme of the in situ fabrication of $\mathrm{Bi}$ nanoparticles on $\mathrm{BiOCl}$ nanosheets in TEM based on the work of Chang et al. [77]. 
the effect has also been reported in the liquid phase, using TEM, STEM, and SEM (scanning electron microscope) techniques [94-97].

In this context, synthesis techniques based on the electron beam irradiation have been employed to obtain silver nanoparticles on a large scale at short reaction times without the presence of chemical residues [93,96,98-102]. For example, Ag nanocrystals have been grown from the dilute solutions of silver nitrate by STEM irradiation [92]. Fine experimental control over the initiation and the growth process is required for practical applications of the technique for fabrication of designer nanostructures for nanoelectronic and nanophotonic applications.

The complete fundamental aspects behind the interaction between electrons with matter remains unsolved, but due to the potential behind it to create new material structures or metastable phases, which have previously not been achieved or are otherwise difficult to produce, envisages the topic as a powerful research area.

\section{New facts: Formation, growth and coalescence of metal nanoparticles}

Because the formation of metal nanoparticles in the high-vacuum system of the electron microscope has not attracted much attention, it is necessary to explore this more intensively. To avoid an overly lengthy review, here we focus only on the formation of metal nanoparticles that are important for both fundamental research and industrial applications. This criterion excludes well-established techniques performed alongside the TEM in which additional hardware addons (gas supplies, filters out techniques, flow-cells, and holders with heating stages) are used to assist the action of the e-beam, such as, the e-beam induced deposition (EBID) [103-106], thermally assisted beam induced crystallization $[107,108]$, and the e-beam lithography $[109,110]$. Topical reviews about the e-beam nanofabrication through methods such as EBID and nanolithography already exist [111].

A literature survey shows that several electron beam induced growth process of metallic $\mathrm{Li}$ [112] and $\mathrm{Na}$ [113] nanoparticles with potential technological applications exist. Wang et al. [114] and MingYu et al. [64] were the first to observe the novel growth mechanism of $\mathrm{Cu}$ isolated nanoparticle. Wang et al. [114] observed the formation of single crystalline $\mathrm{Cu}$ nanorods by the e-beam irradiation and proposed a growth mechanism of $\mathrm{Cu}$ nanorods on carbon films by manipulating electron irradiation on $\mathrm{Cu}$ powders (Figure 2). Ming-Yu et al. [64] reported the evolution of $\mathrm{Cu}$ nanoparticles from the synthesized $\mathrm{CuCl}$ by in situ TEM irradiation. Copper-containing materials such as zeolites can also form high aspect ratio nanorods [115], while Padhi et al. [116] reported that the e-beam irradiation could induce transformation of $\mathrm{Cu}_{2}(\mathrm{OH})_{3} \mathrm{NO}_{3}$ nanoflakes into nanocrystalline $\mathrm{CuO}$.

Kim et al. [117] obtained highly mono-disperse Au nanoparticles when gold(I)-alkane thiolate complexes with supramolecular structures were irradiated by an e-beam in a TEM (Figure 3). Similarly,

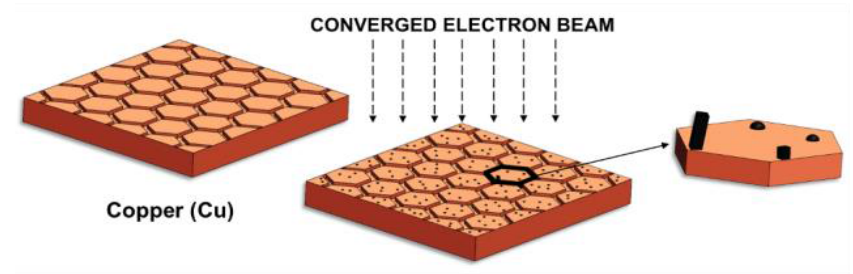

Figure 2: Representative scheme of the in situ fabrication of $\mathrm{Cu}$ nanorods on carbon films in TEM based on the work of Wang et al. [114].

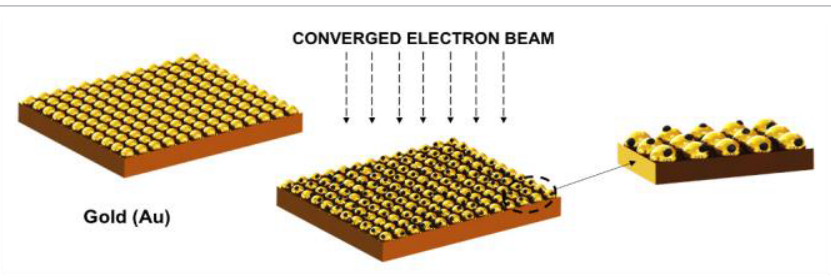

Figure 3: Representative scheme of the real-time in situ protruding of Au nanoparticles in the gold(I)-alkanethiolate complexes in TEM based on the work of Kim et al. [117].

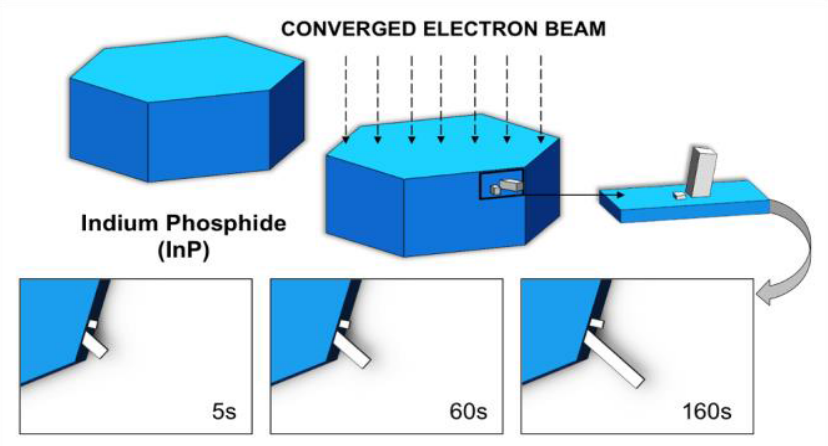

Figure 4: Representative scheme of the real-time in situ long protruding of In nanowire in the InP surface in TEM based on the work of Golberg [118].

Golberg et al. [118] reported that In nanocrystals of different shapes and morphologies were directly grown on the surface of InP nanorods during the e-beam irradiation inside a TEM (Figure 4). These authors were surprisingly able to observe and analyze rarely seen in situ crystal growth of differently-shaped pure In nanosized single crystals on the surface of mother InP without traces of any other elements.

In 2012, Gnanavel and Möbus [119] reported the synthesis of Co nanoparticles of a range of sizes from raw cobalt fluoride powder using e-beam and their characterization in-situ in a TEM. Several e-beam induced growth processes of nanoparticles with potential technological applications, such as metallic $\mathrm{Li}$ [112], $\mathrm{Na}$ [113], $\mathrm{Cu}$ [64], In [118], Co [119], and W [120] have been reported. Del Angel et al. [121] reported the in situ generation of $\mathrm{Ni}$ nanoparticles and thin films by focusing a TEM e-beam over $\mathrm{NiO} / \mathrm{ZrO}_{2}-\mathrm{CeO}_{2}$ and $\mathrm{NiO}$. Recently, Barry et al. [36] have developed a novel technology for formation of metal nanocrystals by synthesizing Os nanoparticles of defined size under e-beam irradiation of an organometallic osmium complex encapsulated in selfspreading polymer micelles. Surprisingly, all these authors reported the formation of metallic nanoparticles as a consequence of the irradiation process but did not comment on the chemical and physical nature of the observed effect. Huang et al. [22] have also discussed the effect of irradiation on $\mathrm{Ti}_{3} \mathrm{AlC}_{2}$ samples by using the e-beam and have shown that during irradiation, $\mathrm{Al}$ atoms are mainly sputtered, while no amorphization occurs along the process.

Previous attempts have successfully demonstrated the growth of Ag nanowires at random locations within the area irradiated by e-beam [97,122-127]. Different research groups have reported the formation of Ag nanoparticles in Ag-containing materials under the influence of e-beam irradiation $[97,123,127,128]$.

Our research group has lately reported an important development that now allows the production of Ag nanoparticles and nanowires on different based Ag materials through irradiation by a widely spread 
Citation: Andrés J, Longo E, Gouveia AF, Costa JPC, Gracia L, et al. (2019) situ Formation of Metal Nanoparticles through Electron Beam Irradiation: Modeling Real Materials from First-Principles Calculations. J Material Sci Eng 7: 461. doi: 10.4172/2169-0022.1000461

Page 4 of 13

e-beam of an FE-SEM or TEM gun, such as $\alpha$ - $\mathrm{Ag}_{2} \mathrm{WO}_{4}$ (Figures 5 and 6) [71], $\beta-\mathrm{Ag}_{2} \mathrm{WO}_{4}$ [129], $\beta-\mathrm{Ag}_{2} \mathrm{MoO}_{4}$ (Figure 7) [35,130,131], $\beta-\mathrm{AgVO}_{3}$ [132], $\mathrm{Ag}_{3} \mathrm{PO}_{4}$ [133], and $\mathrm{Ag}_{2} \mathrm{CrO}_{4}$ (Figure 8) [134]. These semiconductors interact with the e-beam, where the reduction of $\mathrm{Ag}$ cations take place with concomitant formation and growth processes of metallic Ag on the surfaces, forming Ag nanoparticles associated with the semiconductors.

The reasons for the formation of these new structures have been discussed in some recent publications [35,129,133-137]. In particular, Lin et al. [138] have focused on the electronic reconstruction of $\alpha-\mathrm{Ag}_{2} \mathrm{WO}_{4}$ nanorods for visible-light photocatalysis, while $\mathrm{Xu}$ et al. [139] and Thomas et al. [140] evaluated the photocatalytic activity of $\mathrm{a}-\mathrm{Ag}_{2} \mathrm{WO}_{4}$ particles and nanoparticles, respectively. More recently, Sreedevi et al. [141] have analyzed the influence of $8 \mathrm{MeV}$ e-beam irradiation on the structural and optical properties of $\alpha-\mathrm{Ag}_{2} \mathrm{WO}_{4}$

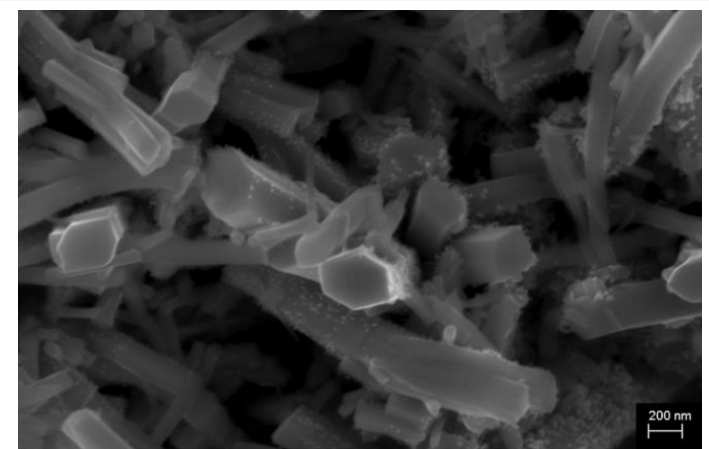

Figure 5: FE-SEM images showing the metallic silver growth in $\alpha-\mathrm{Ag}_{2} \mathrm{WO}_{4}$.

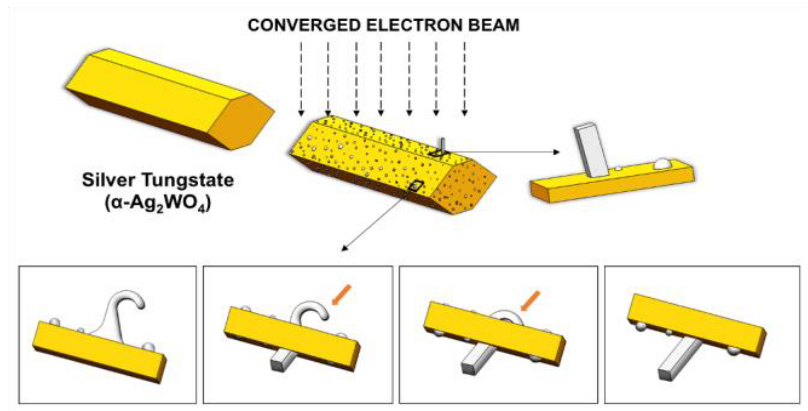

Figure 6: Representative scheme of the real-time in situ formation of $\mathrm{Ag}$ nanoparticles in the $\alpha-\mathrm{Ag}_{2} \mathrm{WO}_{4}$ surface in TEM based on the work of Longo et al. [71].

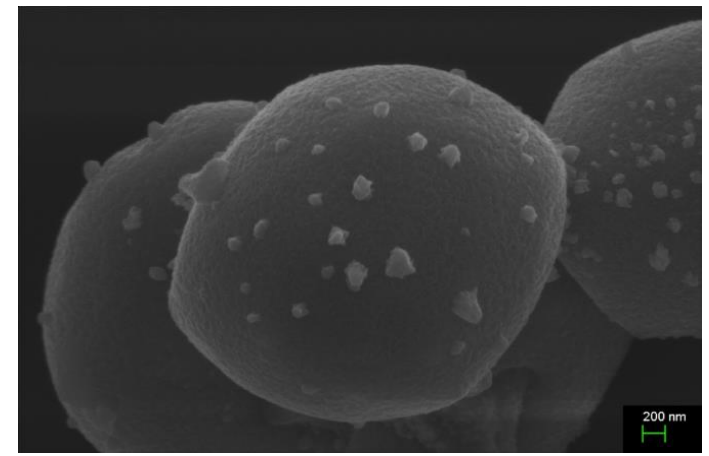

Figure 7: FE-SEM images showing the random growth of metallic silver on the surface of $\beta-\mathrm{Ag}_{2} \mathrm{MoO}_{4}$.

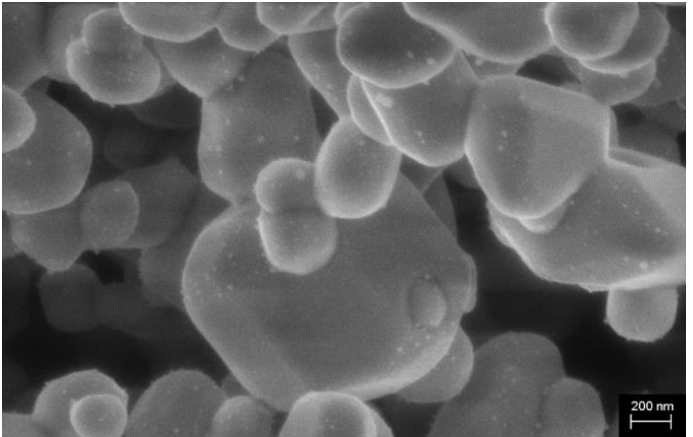

Figure 8: $\mathrm{FE}-\mathrm{SEM}$ images of $\mathrm{Ag}_{2} \mathrm{CrO}_{4}$ with surface silver growth after two minutes of electron irradiation.

nanoparticles with concomitant growth of $\mathrm{Ag}$ nanoparticles on their surfaces. Furthermore, silver closo-boranes $\left(\mathrm{Ag}_{2} \mathrm{~B}_{10} \mathrm{H}_{10}\right.$ and $\left.\mathrm{Ag}_{2} \mathrm{~B}_{12} \mathrm{H}_{12}\right)$ have been found to show extremely fast silver nanofilament growth when excited by electrons during TEM investigations. The Ag nanofilaments can also be reabsorbed back into $\mathrm{Ag}_{2} \mathrm{~B}_{12} \mathrm{H}_{12}$ [142]. The real in situ observation of these processes confirms sample modification in which the e-beam from TEM plays an important role and triggers surface reactions that can change the intra- and interatomic interactions, opening up avenues in a wide range of fields in materials science. This phenomenon has not been reported before and can only be observed in situ at the atomic scale. These interesting properties demonstrate the multifunctionality of silver based compounds. A deep understanding of the interactions between the electrons and the irradiated material is necessary to interpret the processes occurring and to extract the mechanistic information.

However, because of these complex processes, it is difficult to characterize the reaction mechanisms responsible for nanocrystal formation, growth, and coalescence. While it has been established that an e-beam can interact with the specimen through multiple pathways, including [143] e-beam sputtering, radiolysis, electrostatic disruption, hot electron relaxation, and knock-on damage, several authors have postulated that the material must go through the melt during the e-beam-induced fragmentation [144-148].

Two kinds of interaction of the high-energy electrons with the material may be considered. The first is the elastic collision of the electrons with the atomic nucleus that leads to the displacement of the atom by direct momentum transfer knock-on displacement. The other is the inelastic collision that generates electron-hole pairs and direct electron absorption that leads to atomic-electron excitation. There are four possible mechanisms of atomic-electron excitation, namely, ionization of the core electrons, ionization of the valence electrons leading to bond breakage, elevation of the valence electrons to the exciton state, and collective excitation of the valence electrons into plasmons.

As the collective result of atomic-electron excitation, the temperature in the irradiated area increases (beam heating). Moreover, the ionization of the atomic electrons generates a large number of secondary electrons escaping from the specimen with a local positive charge [149]. These observations offer great potential for basic research, but the exact cause of the above phenomena is not clear, thereby leaving a room for further improvement of the understanding.

Next, we discuss the phenomena during the e-beam irradiation in the context of a theoretical framework based on the first-principles 
calculations and experimental data. We will also provide some clues for examining and supporting the chemical activities taking place at the atomic level based on the obtained computational results. The theoretical predictions from this work are expected to be valuable not only for understanding of the physical nature of the induced e-beam irradiation process but also for providing the pathways to find novel nanomaterials with potential for unique magnetic and optical properties and chemical functionalization as demonstrated herein.

The in situ electron irradiation of inorganic solid compounds in FE-SEM and TEM depends on the former network and/or the network modifier, which are the material, irradiation time, electron dosage, and method of synthesis. The chemical reactions, which are initiated by the irradiation of electrons, are non-classical interactions resulting in a solid of high defect density and a new reaction product. This interaction, combined with the imaging of electron microscopy, can be used as a basis for next-generation nanofabrication tools, opening pathways for direct control of matter at the atomic level. A particular emphasis is placed on the e-beam-induced formation of metal nanoparticles conducted inside a TEM and/or FE-SEM, viz. the e-beam is the sole (or largely main) agent triggering and driving the synthesis process.

The modeling of the material properties and the processes from the first-principles calculations is becoming sufficiently accurate to facilitate the understanding of these phenomena observed in materials and to reach a deeper insight into the general description processes by resolving the fundamental mechanisms occurring at the atomic scale during the irradiation of solid materials. Computational materials science is valuable and is becoming increasingly necessary for developing novel functional materials that meet the requirements of the next-generation technology. The interplay between the experimental and the computational approaches at multiple length scales finds many applications in the development and characterization of new phenomena. This review provides a broad and comprehensive overview of recent trends in which predictive modeling capabilities are developed in conjunction with the experiments and advanced characterization techniques to gain a greater insight into structureproperty relationships and to study the physical phenomena and mechanisms.

This work combines the experimental and computational techniques to achieve the best of both methods to provide a tool for understanding of the formation, growth, and coalescence processes of metal nanoparticles provoked by the e-beam irradiation. A tool has been developed in the authors' labs for creating structural models to enable more complete understanding of this phenomenon. Through a number of important examples, we attempt to discuss and summarize some of the important aspects associated with the e-beam interactions, focusing on our experience on some of these materials.

The rest of the paper is organized as follows. First, the motivation and understanding of the present work is presented. Then, we discuss the fundamental principles and explore the advanced applications. Finally, the main lessons learnt from this work are highlighted in the last section.

\section{Motivation and Understanding}

The advent of quantum mechanics in 1926 played a fundamental role in understanding of the behavior of electronic distribution in solids, allowing the rationalization of the existence of insulating, semiconductor, and metallic compounds. Specifically, as stated by Chelikowsky and Cohen [150] research and studies on the electronic structure of semiconductors have played a key role in basic, applied, and computational science, as well as have influenced a large part of the theoretical foundation of modern condensed matter physics and materials science. It can be said that the main challenge in theoretical and experimental studies is to find a common link between the results obtained by means of these two approaches. The accessibility of the systems to be investigated may be different at the atomic level. A wide range of structures and arrangements can theoretically be explored. In many cases, some of these are impossible to obtain experimentally, but the theoretical analysis provides a full picture of the effects present in the real systems.

However, the knowledge of primary processes following the interaction of electron irradiation with solids in vacuum is rather limited and an accurate modeling is still necessary to determine the desired functions from the acquired data. The improved accuracy of measurements and the possibility to combine the information from different experimental techniques require even more flexibility of the models.

The reasons for the present research are manifold and encompass the intellectual excitements of deriving macroscopic performance from the atomic level foundations and the predictive power that quantum mechanical simulations have brought to the field. Our laboratories work by coupling multiple experimental methods and first-principles calculations in a self-consistent computational framework that is essential for the understanding the structure and properties of materials, as recently invoked in an editorial [151] and related papers [152]. An Interview of Nature Materials [153], explains the challenges in materials modeling about the development and innovation, based on a steady mastery of the fundamentals of condensed-matter physics, physical chemistry, and materials science, supported by the knowledge in the fields of computational chemistry and computational materials science. The driving mechanisms and physical causes responsible for the formation of metal nanoparticles on samples irradiated by an e-beam probe are still open to speculation. Therefore, the primary motivation of this work is understanding the nature of in situ formation, growth, and coalescence of metal nanoparticles on different materials to provide fundamental insights into this process. A second motivation is to develop and apply computational quantum chemistry methods to explain this behavior. Another less explored reason for considering quantum phenomena within the chemical systems is the possibility that it could provide new insight into the quantum world of materials. Finally, such cooperative interactions, based on the synergies between computational modeling and experimental characterization of materials across various length scales, find many applications in the development, characterization, and design of complex material systems. In particular, it is possible to exploit this phenomenon to synthesize materials with performance properties significantly better than those using classical electronics or optics and to provide guidelines for a rational design of these materials.

Our ability to characterize, design, and control the properties of a given material depends on the behavior of electrons and electron distribution in the matter [154,155]. Electron distribution encompasses many sciences (chemistry, physics, biology, crystallography, and material science), and electron density, $\rho(r)$ is determined through experiments on crystalline solids through scattering techniques: X-ray, $\gamma$-ray, or electron diffraction. From a theoretical perspective, electron density has an advantage, in that $\rho(\mathrm{r})$ is a quantum mechanically observable.

Accurate modeling of charge distribution has become possible 
only when a significant theoretical background has been developed. Here, we have employed the quantum theory of atoms in molecules (QTAIM), developed by Bader and collaborators [156,157], to analyze the experimental and theoretical electron density distributions $(\rho(r))$ in a molecule or solid as well as to study the properties of $\rho(\mathrm{r})$. These analyses reveal the bonding interactions in a crystal system and the nature of these interactions. The electronic charge of each atom is evaluated using Bader charge analysis within the QTAIM framework, which is a way of dividing a solid into atoms on the basis of electronic charge density. Finding zero flux surfaces between two atoms allows the charge of each atom to be calculated.

As the formation of metallic nanoparticles after the electron irradiation is a quantum phenomenon, we have performed quantum mechanical calculations to understand the structural and electronic modifications of material that are observed experimentally. In the calculations, electrons are introduced one by one in the unit cell of material, followed by the redistribution of extra electrons by simultaneous geometrical optimization on both the lattice parameters and the atomic positions.

The irradiation of electrons into inorganic compounds can be analyzed in various ways; however, the structure of the material, i.e., the local coordination (clusters) of the atoms as the building block of the material, is highly relevant. The interaction between these clusters with the electron depends on the electronic cluster affinity. Thus, there may be interaction with the network former and/or network modifier. Moreover, two important parameters are time irradiation and electron dosage.

\section{Case Study}

In the following figures, we can select different examples where the e-beam irradiation is capable of provoking the formation of metal particles, such as $\mathrm{Ag}$, In, $\mathrm{Cu}$, and $\mathrm{Au}$. The electron irradiation of the beam on inorganic compounds versus time has several stages: cluster outlet formation in the crystal surface, segregation and formation of nanoparticles via a cluster assembly process, and subsequent growth stage. In this last step, the formed clusters can yield nanoparticles with defined structure with appropriate restructuration to obtain the crystal. This is a new method for manufacturing semiconductor multifunctionality. This hybrid semiconductor can give rise to semiconductors with different properties and can also be molded depending on the time and exposure density of the radiation by electrons. These two parameters can change the concentration of vacancies in the bulk and on the metal surface. The important aspect is that all changes are generated in the same material and can be monitored in situ by FE-SEM or TEM.

Now, we show how the first-principles calculations, within a QTAIM framework, have been carried out to provide deeper insight and understanding of the observed nucleation and early evolution of $\mathrm{Ag}$ nanoparticles in silver phosphate $\left(\mathrm{Ag}_{3} \mathrm{PO}_{4}\right)$ crystals, driven by an accelerated e-beam from an electronic microscope under high vacuum. $\mathrm{Ag}_{3} \mathrm{PO}_{4}$ crystallizes in a body-centered cubic structure with space group $P-43 n$ [158]. Currently, this material has received considerable attention from the scientific community because of its photooxidative applications [159-164].

A theoretical and experimental study on the structural, morphological, and optical properties of $\mathrm{Ag}_{3} \mathrm{PO}_{4}$ powders synthesized by the co-precipitation $(\mathrm{CP})$ route and processed in a microwaveassisted hydrothermal (MAH) system at $150^{\circ} \mathrm{C}$ for different times was recently reported [133]. These powders were structurally characterized by means of X-ray diffraction (XRD), Rietveld refinements, and microRaman (MR) spectroscopy. The first-principles density functional theory (DFT) calculations were carried out to understand the physical phenomena involved in the growth stages of metallic Ag nanostructures on the surface of $\mathrm{Ag}_{3} \mathrm{PO}_{4}$ microparticles. Finally, the ultraviolet-visible (UV-Vis) absorption spectroscopy and photoluminescence (PL) measurements at the room temperature were performed to verify the correlation between the optical properties and the structural orderdisorder in these phosphates.

First-principles total-energy calculations were carried out within the periodic DFT framework using the VASP program $[165,166]$. The Kohn-Sham equations were solved using the screened hybrid functional proposed by Heyd, Scuseria, and Ernzerhof (HSE) $[167,168]$ in which a percentage of exact non-local Fock exchange is added to the Perdew, Purke, and Ernzerhof functional (30\%), with a screening of $0.11 \mathrm{bohr}$ ${ }^{1}$ applied to partition the Coulomb potential into the long range and short range terms, as reported in some recent papers $[169,170]$. The number of electrons in the bulk structure has been gradually increased and the corresponding crystal structure (volume of the unit-cell and the atomic positions) is optimized in order to find the minima on the potential energy hypersurface. The Bader's QTAIM [156,171,172] is a well-recognized tool used to analyze the electron density, to describe interatomic interactions, and to rationalize chemical bonding. The different strong and weak interactions between two atoms can be determined unequivocally from the QTAIM calculations. Moreover, concepts such as $(3,-1)$ bond critical points (BCPs), their respective bond paths (BPs), and $\mathrm{L}(\mathrm{r})=-\nabla^{2} \rho(\mathrm{r})$ maps can be analyzed to reveal the nature of these interactions.

In the $\mathrm{Ag}_{3} \mathrm{PO}_{4}$ modeled structure, both $\mathrm{Ag}$ and $\mathrm{P}$ atoms are connected to four $\mathrm{O}$ atoms, resulting in distorted tetrahedral $\left[\mathrm{AgO}_{4}\right]$ and $\left[\mathrm{PO}_{4}\right]$ clusters, as presented in Figure 9.

Figure 10 shows the FEG-SEM images of $\mathrm{Ag}_{3} \mathrm{PO}_{4}$ powders before and after 5-min exposure to the e-beam (accelerated at $15 \mathrm{kV}$ ) of the SEM. When these microparticles were subjected to the influence of the e-beam for $5 \mathrm{~min}$, it was verified that anisotropic growth of pre-existing metallic Ag nanostructures took place, behaving as active growth nuclei. This behavior is practically new for $\mathrm{Ag}_{3} \mathrm{PO}_{4}$ powders, but it has been reported in other materials containing $\mathrm{Ag}$ in their compositions $[71,132,134,136,173]$, giving rise to interesting applications as sensors, photoluminescent materials and visible-light photocatalysts. Therefore, e-beam is able to stimulate the nucleation and growth of metallic Ag filaments on $\alpha-\mathrm{Ag}_{3} \mathrm{PO}_{4}$ crystals. According to these authors, the excess of electrons led to the appearance of surface defects in this phosphate,

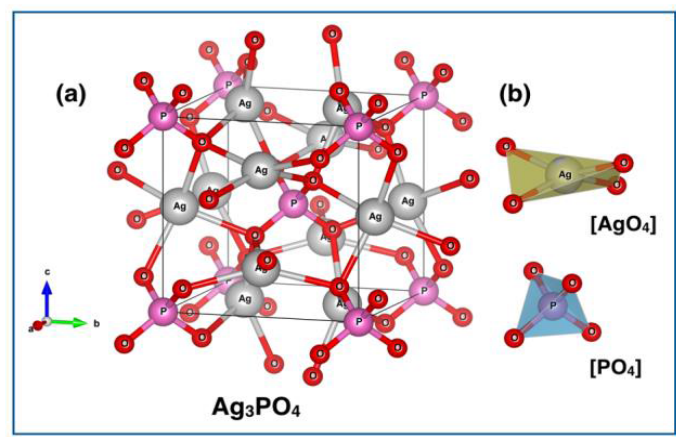

Figure 9: (a) Schematic representation of the cubic $\mathrm{Ag}_{3} \mathrm{PO}_{4}$ structure and (b) illustration of both tetrahedral $\left[\mathrm{AgO}_{4}\right]$ and $\left[\mathrm{PO}_{4}\right]$ clusters. 
causing a continuous axial flow of Ag filaments. In another paper [173], it has been reported that the growth of these filaments potentiates the bacteriostatic and bactericidal activities of $\alpha-\mathrm{Ag}_{2} \mathrm{WO}_{4}$, especially in combating Staphylococcus aureus. The appearance of Ag nanoparticles was explained through the reduction induced by photogenerated electrons during photocatalysis. Therefore, such features imply that materials containing Ag exhibit a high growth potential for the development of irregular Ag structures on the particles.

In addition, in order to confirm this growth phenomenon of metallic Ag nanostructures in $\mathrm{Ag}_{3} \mathrm{PO}_{4}$ powders, a TEM microscope was employed coupled with an energy dispersive $\mathrm{x}$-ray spectroscopy (EDS) system, enabling local chemical analysis of elements in each individual microparticle. For $5 \mathrm{~min}$, the samples were subjected to the e-beam of the TEM microscope, in which two distinct regions were selected in the focused microparticles, as shown in Figure 11. Region 1 was chosen on the Ag growth nucleus, while region 2 was selected near the center of a single microparticle. As expected, the EDS results confirmed the electrons promoted the random growth of metallic Ag nanostructures because of the large percentage of $\mathrm{Ag}$ atoms, especially detected in the region 1 of the microparticles. In principle, these $\mathrm{Ag}$ atoms migrate from matrix to surface, causing a structural and morphological alteration (defects). The $\mathrm{C}$ and $\mathrm{Cu}$ atoms observed in all EDS analyses arise from the 300 mesh $\mathrm{Cu}$ grids used in the TEM.

Regarding the experimental results reported in Figures 10 and 11 , the theoretical calculations were employed to understand the phenomenon of electron absorption responsible for the growth of Ag nanostructures. The calculated values for the lattice parameters, $\mathrm{Ag}-\mathrm{O}, \mathrm{P}-\mathrm{O}$, and $\mathrm{Ag}-\mathrm{Ag}$ bond lengths, and band gap energy $\left(E_{\text {gap }}\right)$ as a function of the number of electrons added $(N)$ are shown in Table 1.

In Table 1, a clear increase in the lattice parameters as well as Ag-O and $\mathrm{Ag}-\mathrm{Ag}$ bond lengths is observed. When the addition of up to five electrons is taken into account in the calculations, the data reveal an increase in $\mathrm{Ag}-\mathrm{O}$ bond lengths, while the $\mathrm{P}-\mathrm{O}$ bond lengths remain practically constant. This behavior can be probably associated with the elastic collisions of $\left[\mathrm{PO}_{4}\right]$ clusters compared to the strong inelastic collisions of $\left[\mathrm{AgO}_{4}\right]$ clusters. Hence, the theoretical analyses point out the addition of electrons is responsible for structural alterations and formation of defects on the $\left[\mathrm{AgO}_{4}\right]$ clusters, generating the ideal conditions for the growth of $\mathrm{Ag}$ nanostructures.

The Bader charge density of $\mathrm{Ag}, \mathrm{P}$, and $\mathrm{O}$ centers as a function of $N$ is collected in Table 2. In this calculation, $\mathrm{Ag}$ atoms of $\left[\mathrm{AgO}_{4}\right]$ clusters have a higher tendency to be reduced rather than the $\mathrm{P}$ atoms. Particularly at $N=5$, all $\mathrm{Ag}$ atoms are almost reduced (from $0.64 \mathrm{e}$ to $0.02 \mathrm{e}$ ), whereas for $\mathrm{P}$ atoms a constant value of the electron density is

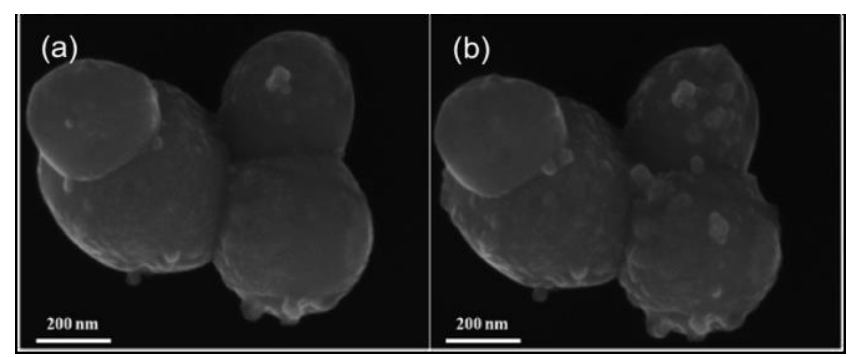

Figure 10: (a) FEG-SEM images (considered as time zero) of $\mathrm{Ag}_{3} \mathrm{PO}_{4}$ powders synthesized by the CP route and processed in a MAH system for $32 \mathrm{~min}$. (b) FEG-SEM images of the same samples after five minutes of exposure to an accelerated electron beam.

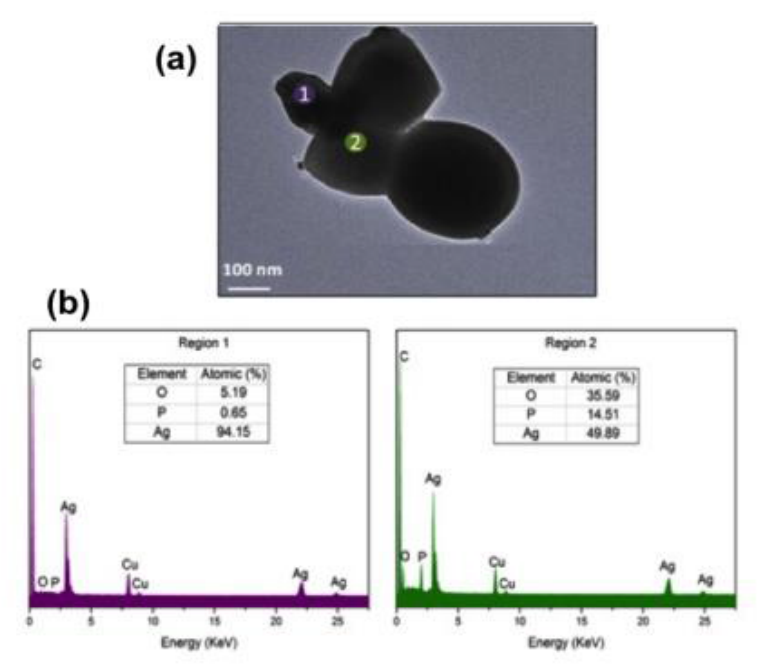

Figure 11: (a) TEM images after five minutes of exposure to the electron beam for $\mathrm{Ag}_{3} \mathrm{PO}_{4}$ powders synthesized by the $\mathrm{CP}$ route and those processed in a $\mathrm{MAH}$ system for $16 \mathrm{~min}$, illustrating the two regions (purple and green circles) used in the chemical composition analysis by EDS. (b) EDS results of $\mathrm{Ag}_{3} \mathrm{PO}_{4}$ powders synthesized by the $\mathrm{CP}$ route and those processed in a MAH system for $16 \mathrm{~min}$

kept (slight decrease of 0.05 units at $N=5$ ). Consequently, the electron excess enforced in the material is transferred from one cluster to another through the $\mathrm{Ag}_{3} \mathrm{PO}_{4}$ framework, so that the formation and growth processes of $\mathrm{Ag}$ involve adjacent $\left[\mathrm{AgO}_{4}\right]$ clusters. In addition, the charge density $\left(\rho_{b c p}\right)$ at the $(3,-1)-(\mathrm{BCPs})$ as well as its Laplacian $\left(\nabla^{2} \rho_{b c p}\right)$ in $\mathrm{Ag}-\mathrm{O}$ bonds of $\left[\mathrm{AgO}_{4}\right]$ clusters are accessible in Table 2. The addition of electrons in the material provokes an interesting reduction in the theoretical $\rho_{b c p}$ and $\nabla^{2} \rho_{b c p}$ values, indicating that the $\mathrm{Ag}-\mathrm{O}$ bonds become less strong to favor the formation of metallic Ag. This same behavior has been also reported in recently published papers $[71,132,134,136]$.

Figure 12a shows the upper part of the valence band (VB) and the lower part of the conduction band (CB) of density of states (DOS) plot for Ag atoms, considering neutral $\mathrm{Ag}_{3} \mathrm{PO}_{4}(N=0)$ and the addition of five electrons $(N=5)$. The Fermi level is placed at energy of $0 \mathrm{eV}$. A general analysis of the DOS shows a high contribution of the $s$ orbitals in the lower part of CB for all Ag atoms. The doublet spin multiplicity is noticed for $N=3$ and 5 , in which the alpha (up) and beta (down) electronic contributions are not symmetric. For $N=2$ and 4 , the spin electronic configuration more stable is the singlet, as the neutral condition of $\mathrm{Ag}_{3} \mathrm{PO}_{4}$. Higher reduction in $E_{\text {gap }}$ is noted when $N$ is 5 (Table 1). Theoretically, the shift of the $s$ band of Ag atoms is probably caused by the interaction of the sample with the e-beam. 2D charge density maps related to the interaction of $\left[\mathrm{AgO}_{4}\right]-\left[\mathrm{PO}_{4}\right]$ clusters and $\left[\mathrm{AgO}_{4}\right]-\left[\mathrm{AgO}_{4}\right]$ clusters for $\mathrm{N}=0$ and $N=5$ are illustrated in Figure $9 \mathrm{~b}$ and $9 \mathrm{c}$, respectively. The regions with high and low charge densities are specified by the concentration of charge lines around the atoms. When compared to the charge density maps of $\left[\mathrm{AgO}_{4}\right]-\left[\mathrm{PO}_{4}\right]$ clusters in Figure 9a, the results disclose a decrease in the electronic charge density between $\mathrm{Ag}$ and $\mathrm{O}$ atoms for $\mathrm{N}$ from 0 to 5. Thus, the $\mathrm{Ag}-\mathrm{O}$ bond lengths are enlarged due to the perturbation caused in the system with the addition of electrons $(N=5)$, while the $\mathrm{P}-\mathrm{O}$ bond lengths persist practically constant. This behavior is probably associated with the strong covalent character of $\mathrm{P}-\mathrm{O}$ bonds compared to the ionic character of $\mathrm{Ag}-\mathrm{O}$ bonds. In addition, the charge density maps presented in Figure $9 \mathrm{~b}$ indicate the interactions of $\left[\mathrm{AgO}_{4}\right]-\left[\mathrm{AgO}_{4}\right]$ 
Citation: Andrés J, Longo E, Gouveia AF, Costa JPC, Gracia L, et al. (2018) situ Formation of Metal Nanoparticles through Electron Beam Irradiation: Modeling Real Materials from First-Principles Calculations. J Material Sci Eng 7: 461. doi: 10.4172/2169-0022.1000461

Page 8 of 13

\begin{tabular}{|c|c|c|c|c|c|}
\hline \multirow[t]{2}{*}{$N$} & \multirow[t]{2}{*}{ Lattice parameter a $(\AA)$} & \multicolumn{3}{|c|}{ Bond lengths $(\AA)$} & \multirow[t]{2}{*}{$E_{\text {gap }}(\mathrm{eV})$} \\
\hline & & $\mathrm{Ag}-\mathrm{O}$ & $\mathrm{P}-\mathrm{O}$ & $\mathrm{Ag}-\mathrm{Ag}$ & \\
\hline 0 & 6.0244 & 2.37 & 1.56 & 3.01 & 2.72 \\
\hline 1 & 6.1698 & 2.45 & 1.56 & 3.08 & 2.53 \\
\hline 2 & 6.3107 & 2.52 & 1.56 & 3.15 & 2.30 \\
\hline 3 & 6.4496 & 2.59 & 1.56 & 3.22 & 1.95 \\
\hline 4 & 6.5800 & 2.66 & 1.56 & 3.29 & 1.87 \\
\hline 5 & 6.6991 & 2.72 & 1.55 & 3.40 & 1.60 \\
\hline
\end{tabular}

Table 1: Results obtained by the addition of electrons in the $\mathrm{Ag}_{3} \mathrm{PO}_{4}$ structure.

\begin{tabular}{|c|c|c|c|c|}
\hline $\mathbf{N}$ & $\mathbf{A g}$ & $\mathbf{P}$ & $\mathbf{0}$ & $\boldsymbol{\rho}_{\text {bcp }}$ \\
\hline 0 & 0.640 & 3.664 & -1.396 & 0.31 \\
\hline 1 & 0.528 & 3.633 & -1.429 & 0.27 \\
\hline 2 & 0.411 & 3.600 & -1.459 & 0.23 \\
\hline 3 & 0.286 & 3.602 & -1.490 & 0.20 \\
\hline 4 & 0.156 & 3.610 & -1.520 & 0.18 \\
\hline 5 & 0.021 & 3.607 & 2.51 & \\
\hline
\end{tabular}

Table 2: Bader charge density of $\mathrm{Ag}, \mathrm{P}$ and $\mathrm{O}$ centers and charge density at the $(3,-1) \mathrm{BCPs}$ and its Laplacian in $\mathrm{Ag}-\mathrm{O}$ bonds of $\left[\mathrm{AgO} \mathrm{O}_{4}\right]$ clusters as a function of $N$.

clusters also become weaker when $N$ is increased from 0 to 5 , in good agreement with the $\mathrm{Ag}-\mathrm{Ag}$ distances presented in Table 1. Therefore, both behaviors theoretically achieved in Figure $9 \mathrm{a}$ and $9 \mathrm{~b}$ can be associated with the growth of metallic Ag nanostructures (Figure 12).

Clusters of $\left[\mathrm{AgO}_{4}\right]$ interact with the received electrons when the surface of $\mathrm{Ag}_{3} \mathrm{PO}_{4}$ is irradiated with an e-beam, occasioning the creation of Ag vacancy and the reduction of silver. Furthermore, Ag migrates from the bulk to the surface and under persistent electron irradiation it is possible observe the growth of nanocrystal of silver. Since silver is formed at zones where negatively charged vacancies are present in the crystal lattice, a short- and medium-range disordering within the semiconductor is induced. The regions with metallic silver vacancy exhibit a $p$-type semiconducting behavior. Since $\mathrm{Ag}_{3} \mathrm{PO}_{4}$ is an $n$-type semiconductor, an $n / p$ interface is formed in this zone. This interface increases the polarization and consequently, electron/hole recombination develops more difficult.

Careful experiments and coupled theory, modeling, and simulation will be required to pick apart the origins of the relationship among the local, intermediate, and long-range structure and material properties. Experimental probes can provide more structural information on short and long-range order in materials; however, their structures over the medium range are still understood poorly. Theoretical calculations and computer simulations can complement the experimental methods and they have revealed new insights into medium range order, surface structures, and dynamic changes in local structures.

The insights gained from our studies are not only of fundamental importance but also of technological interest because the microscopic behaviors reported here, together with those reported earlier, not only serve as model test systems for basic studies, but may also serve as a novel design avenue that can be exploited for the growth of various micro- and nanostructures. The integration of materials simulation into the design procedure can be used both to screen the most promising candidate materials and to expedite the materials characterization and application, for example by providing the spectral signatures required to identify the material with proposed properties and applications.

\section{Conclusions}

The interaction of waves or particles with materials is a topic that is increasingly attracting the interest of scientists since the past two decades, and it will continue to be a fascinating field in the coming (a)
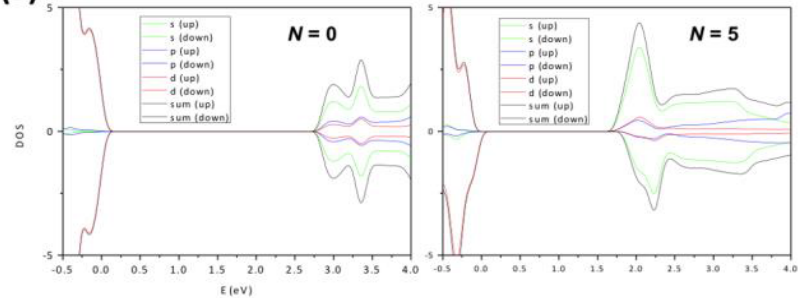

(b)
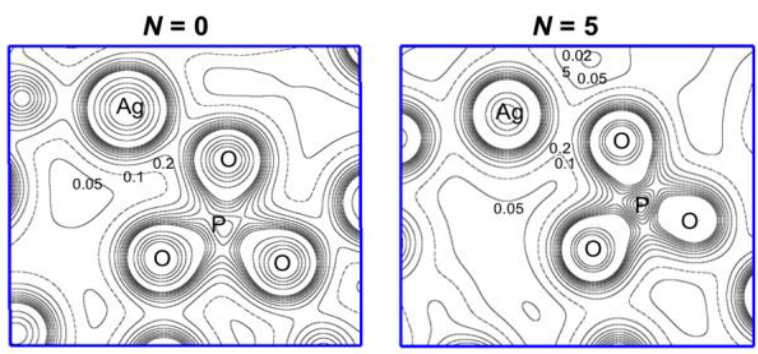

(c)
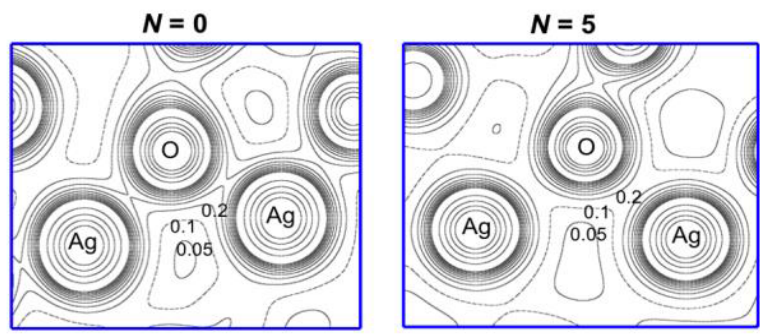

Figure 12: (a) DOS plots analyzing the upper part of the VB and the lower part of the $\mathrm{CB}$ of different $\mathrm{Ag}$ atoms where $\mathrm{N}=0$ and $5.2 \mathrm{D}$ charge density maps of (b) $\left[\mathrm{AgO}_{4}\right]-\left[\mathrm{PO}_{4}\right]$ clusters and (c) $\left[\mathrm{AgO}_{4}\right]-\left[\mathrm{AgO}_{4}\right]$ clusters, respectively, for the conditions of $N=0$ and 5 .

years. This is because many challenging fundamental problems have not been solved, especially concerning the interaction of electrons with matter and also because potential advanced technologies will emerge because of the impressive capability of this phenomenon to create new material structures and hence functionalities. Understanding the physical mechanisms of such induced phenomena is extremely challenging.

With the current development of electron beam sources, the use 
Citation: Andrés J, Longo E, Gouveia AF, Costa JPC, Gracia L, et al. (2018) situ Formation of Metal Nanoparticles through Electron Beam Irradiation: Modeling Real Materials from First-Principles Calculations. J Material Sci Eng 7: 461. doi: 10.4172/2169-0022.1000461

of TEM and affiliated techniques is no more limited to imaging or chemical analysis, but has been rather extended to nanoengineering. Electron beam irradiation is a promising approach to fabricate nanoparticles for various applications. Further advancement of this approach and rational design of experiments require improved mechanistic understanding of the physical process, and atomistic modeling and simulation have been widely employed to reach this end. The aim of this review is to present a critical overview of the current state of the technologies used for studying in situ formation, growth, and coalescence of metal nanoparticles on different material by electron irradiation in TEM and affiliated techniques, providing a greater insight into structure-property relationships and enabling the study of various physical phenomena and mechanisms.

In the present work, we focus on specific areas where theory/ computation and experiment have converged to provide unprecedented insights into physical mechanisms that govern in situ formation of metal nanoparticles through e-beam irradiation. The ability to directly compare theoretical results with experimental measurements is essential for the validation of the computational approach. In addition, it empowers the theoretical work to help interpret and explain the experimental observations and ultimately to reliably predict the structures and properties that can be experimentally implemented and observed. We tried to summarize the important progress made in elucidating such structures using first-principles calculations, and a theoretical framework is developed to determine the physical principles involved in the formation of metal nanoparticles on different materials.

Using robust experimental and theoretical tools, scientists can now push the limit of investigations to the ultimate level of individual atoms and single bonds. If this knowledge can be transformed to develop useful materials, it will provide exciting opportunities to engineer innovative and novel materials for new applications. This has been the guiding light of our work in the last 20 years, both in Castellon at University Jaume I, Spain (Theoretical and Computational Chemistry Group) and São Carlos at the Center for the Development of Functional Materials (CDMF), focusing on three major areas of functional materials, namely energy, environment, and health. This can be summarized as follows: Experiments+Theory (Simulations and FirstPrinciples Calculations)+Interdisciplinary Collaboration=Fundamental Insights+Technological Applications.

\section{Dedication}

"We are saddened by the passing on May 17, 2016, of our dear friend and colleague José Arana Varela. This work is a tribute to his memory."

\section{Acknowledgements}

This perspective summarized herein has been the collective effort and the result of long-standing collaboration among many colleagues, postdoctoral fellows, and students over the past 25 years and we are grateful to them for their collaboration and friendship.

The authors gratefully acknowledge the spirited, talented, and gifted group of graduate students, both doctorate and post-doctorate colleagues, as well as the researchers in our laboratory, both from the present and the past, whom we have had the opportunity and good fortune to work with. Their personal and professional progression as scientists have provided the true pleasure and satisfaction in conducting this work. Without their efforts, this review would not have been completed. We wish to thank the members of our research groups, whose work has been cited in the references, for their dedication and hard work. In particular, we express our gratitude to Dr. Diogo Volanti, Dr. W. Avansi Jr., Dr. Valeria Longo, Dr. Patricio González-Navarrete, Dr. Içamira Costa, Dr. Roman Alvarez, Pablo Lemos, Marcelo Assis, Regiane Oliveira, Dr. Laecio Cavalcante, Prof. Dr. Miguel San Miguel, and Prof. Dr. Edison da Silva.

Special appreciation is extended to Rorivaldo Camargo for the TEM and FESEM analysis. We also acknowledge the Serveid' Informàtica, Universitat Jaume
I, for generous allotment of the computer time. We are thankful to Dr. Silvia Ferrer for critical reading of the manuscript and help in the preparation of the references and the original figures.

This work was financially supported by the following Spanish and Brazilian research funding institutions: Generalitat Valenciana for Prometeo II/2014/022, ACOMP/2014/270, ACOMP/2015/1202, Ministerio de Economia y Competitividad (Spain) project CTQ2015-65207-P, Programa de Cooperación Cientifíca con lberoamerica (Brasil) of Ministerio de Educación (Spanish Brazilian program, PHB2009-0065-PC andPHBP14-00020, Fundação de Amparo à Pesquisa do Estado de São Paulo (FAPESP 2013/07296-2, 2013/26671-9 and 2017/072408), Conselho Nacional de Desenvolvimento Científico e Tecnológico (CNPq), and Coordenação de Aperfeiçoamento de Pessoal de Nivel Superior (CAPES).

\section{References}

1. Egerton RF, Li P, Malac M (2004) Radiation damage in the TEM and SEM Micron 35: 399-409.

2. Williams DB, Carter CB (2009) Transmission electron microscopy: A textbook for materials science. (2ndedn), Springer pp: 23-38.

3. Hu YH, Ruckenstein E (2006) Nano-structured Li2O from LiOH by electronirradiation. Chem Phys Lett 430: 80-83.

4. Jiang $\mathrm{N}$, Spence $\mathrm{JCH}$ (2012) On the dose-rate threshold of beam damage in TEM. Ultramicroscopy 113: 77-82.

5. Xu W, Zhang Y, Cheng G, Jian W, Millett PC, et al. (2013) In-situ atomic-scale observation of irradiation-induced void formation. Nat Commun 4: 2288.

6. Golberg D, Costa PMFJ, Mitome M, Bando Y (2009) Properties and engineering of individual inorganic nanotubes in a transmission electron microscope. J Mater Chem 19: 909-920

7. Gao Y, Bando Y (2002) Nanotechnology: Carbon nanothermometer containing gallium. Nat 415: 599-599.

8. Duan H, Xie E, Han L, Xu Z (2008) Turning PMMA Nanofibers into Graphene Nanoribbons by In Situ Electron Beam Irradiation. Adv Mater 20: 3284-3288.

9. Gan Y, Banhart F (2008) The Mobility of Carbon Atoms in Graphitic Nanoparticles Studied by the Relaxation of Strain in Carbon Onions. Adv Mater 20: 4751-4754.

10. Yang Y, Scholz R, Berger A, Kim DS, Knez M, et al. (2008) Transmission Electron Microscopy in situ Fabrication of ZnO/Al2O3 Composite Nanotubes by Electron-Beam-Irradiation-Induced Local Etching of ZnO/Al2O3 Core/Shel Nanowires. Small 4: 2112-2117.

11. Zhang W, Zheng WT (2015) Transmission electron microscopy finds plenty of room on the surface. Phys Chem Chem Phys 17: 14461-14469.

12. Xu T, Sun L (2015) Dynamic In-Situ Experimentation on Nanomaterials at the Atomic Scale. Small 11: 3247-3262.

13. Xu Y, Shi L, Zhang $X$, Wong K, Li Q (2011) The electron beam irradiation damage on nanomaterials synthesized by hydrothermal and therma evaporation methods-An example of ZnS nanostructures. Micron 42: 290-298.

14. Krasheninnikov AV, Nordlund K (2010) lon and electron irradiation-induced effects in nanostructured materials. J Appl Phys 107: 071301.

15. Zeng $H$, Wang $Q$, Rao $Y$ (2015) Ultrafine [small beta]-AgVO3 nanoribbons derived from [small alpha]-AgVO3 nanorods by water evaporation method and its application for lithium ion batteries. RSC Advances 5: 3011-3015.

16. Henderson R (1995) The potential and limitations of neutrons, electrons and X-rays for atomic resolution microscopy of unstained biological molecules. $Q$ Rev Biophys 28: 171-193.

17. Tham D, Nam CY, Fischer JE (2006) Microstructure and Composition of Focused-lon-Beam-Deposited Pt Contacts to GaN Nanowires. Adv Mater 18: 290-294.

18. Gangnaik AS, Georgiev YM, Holmes JD (2017) New Generation Electron Beam Resists: A Review. Chem Mater 29: 1898-1917.

19. Jiang N (2016) Electron beam damage in oxides: a review. Rep Prog Phys 79 016501

20. El Mel AA, Bittencourt C (2016) In situ conversion of nanostructures from solid to hollow in transmission electron microscopes using electron beam. Nanoscale 8: 10876-10884. 
Citation: Andrés J, Longo E, Gouveia AF, Costa JPC, Gracia L, et al. (2018) situ Formation of Metal Nanoparticles through Electron Beam Irradiation: Modeling Real Materials from First-Principles Calculations. J Material Sci Eng 7: 461. doi: 10.4172/2169-0022.1000461

21. Gonzalez-Martinez IG, Bachmatiuk A, Bezugly V, Kunstmann J, Gemming T, et al. (2016) Electron-beam induced synthesis of nanostructures: A review. Nanoscale 8: 11340-11362.

22. Huang X, Feng Y, Dou Y, Tang H, Ding D, et al. (2016) Effect of electron irradiation on Ti3AIC2. Scr Mater 113: 114-117.

23. Krasheninnikov AV, Banhart F (2007) Engineering of nanostructured carbon materials with electron or ion beams. Nat Mater 6: 723-733.

24. Li J, Banhart F (2004) The Engineering of Hot Carbon Nanotubes with a Focused Electron Beam. Nano Lett 4: 1143-1146.

25. Noh KW, Liu Y, Sun L, Dillon SJ (2012) Challenges associated with in-situ TEM in environmental systems: The case of silver in aqueous solutions. Ultramicroscopy 116: 34-38.

26. McCartney MR, Crozier PA, Weiss JK, Smith DJ (1991) Electron-beam-induced reactions at transition-metal oxide surfaces. Vacuum 42: 301-308.

27. Xu Q, Wu MY, Schneider GF, Houben L, Malladi SK, et al. (2013) Controllable Atomic Scale Patterning of Freestanding Monolayer Graphene at Elevated Temperature. ACS Nano 7: 1566-1572.

28. Borrnert F, Fu L, Gorantla S, Knupfer M, Büchner B, et al. (2012) Programmable Sub-nanometer Sculpting of Graphene with Electron Beams. ACS Nano 6: 10327-10334.

29. Withers F, Bointon TH, Dubois M, Russo S, Craciun MF (2011) Nanopatterning of Fluorinated Graphene by Electron Beam Irradiation. Nano Lett 11: 39123916.

30. Park JH, Schneider NM, Grogan JM, Reuter MC, Bau HH, et al. (2015) Control of Electron Beam-Induced Au Nanocrystal Growth Kinetics through Solution Chemistry. Nano Lett 15: 5314-5320.

31. Chen Y, Huang Y, Liu N, Su J, Li L, et al. (2015) Fabrication of nanoscale Ga balls via a Coulomb explosion of microscale silica-covered $\mathrm{Ga}$ balls by TEM electron-beam irradiation. Sci Rep 5: 11313.

32. Zeng $\mathrm{H}$, Li X, Zhao H, Ning X, Xu J (2015) In situ electron beam irradiationdriven formation of quantum dots. RSC Advances 5: 25717-25722.

33. Ke X, Bittencourt C, Bals S, Van Tendeloo G (2013) Low-dose patterning of platinum nanoclusters on carbon nanotubes by focused-electron-beaminduced deposition as studied by TEM. Beilstein J Nanotechnol 4: 77-86.

34. Nakamura R, Ishimaru M, Yasuda H, Nakajima H (2013) Atomic rearrangements in amorphous $\mathrm{Al} 2 \mathrm{O} 3$ under electron-beam irradiation. J Appl Phys 113: 064312.

35. Andrés J, Ferrer MM, Gracia L, Beltran A, Longo VM, et al. (2015) A combined experimental and theoretical study on the formation of $\mathrm{Ag}$ filaments on $\beta$ $\mathrm{Ag} 2 \mathrm{MoO} 4$ induced by electron irradiation. Part Part Syst Charact 32: 646-651.

36. Pitto-Barry A, Perdigao LMA, Walker M, Lawrence J, Costantini G, et al (2015) Synthesis and controlled growth of osmium nanoparticles by electron irradiation. Dalton Trans 44: 20308-20311.

37. El Mel AA, Molina-Luna L, Buffière M, Tessier PY, Du K, et al. (2014) Electron Beam Nanosculpting of Kirkendall Oxide Nanochannels. ACS Nano 8: 18541861.

38. Lewis EA, Slater TJA, Prestat E, Macedo A, O'Brien P, et al. (2014) Realtime imaging and elemental mapping of $\mathrm{AgAu}$ nanoparticle transformations. Nanoscale 6: 13598-13605

39. Huang CW, Hsin CL, Wang CW, Chu FH, Kao CY, et al. (2012) Direct observation of melting behaviors at the nanoscale under electron beam and heat to form hollow nanostructures. Nanoscale 4: 4702-4706.

40. Zhang H, Deng X, Zhang J, Xue D, Huang Y, et al. (2015) Phase transformation of Sn-based nanowires under electron beam irradiation. J Mater Chem C 3 : 5389-5397.

41. Winkler N, Peterlechner M, Wilde G (2015) Controlling crystallization, phase transformation and magnetic properties of amorphous FeNiP by annealing in nano-confinement. J Mater Chem C 3: 7543-7551.

42. Yang Z, Walls M, Lisiecki I, Pileni MP (2013) Unusual Effect of an Electron Beam on the Formation of Core/Shell $(\mathrm{Co} / \mathrm{CoO})$ Nanoparticles Differing by Their Crystalline Structures. Chem Mater 25: 2372-2377.

43. Wei X, Tang DM, Chen Q, Bando Y, Golberg D (2013) Local Coulomb Explosion of Boron Nitride Nanotubes under Electron Beam Irradiation. ACS Nano 7: 3491-3497.
44. Duan X, Kim T, Han L, Ma J, Du X, et al. (2013) Formation of Alumina Nanocapsules by High-Energy-Electron Irradiation of Na-dawsonite Nanorods. Sci Rep 3: 3218.

45. Park GS, Lee EK, Lee JH, Park J, Kim SK, et al. (2009) A High-Density Array of Size-Controlled Silicon Nanodots in a Silicon Oxide Nanowire by ElectronStimulated Oxygen Expulsion. Nano Lett 9: 1780-1786.

46. Herman DAJ, Cheong S, Banholzer MJ, Tilley RD (2013) How hollow structures form from crystalline iron-iron oxide core-shell nanoparticles in the electron beam. Chem Commun 49: 6203-6205.

47. Sundararajan JA, Kaur M, Qiang Y (2015) Mechanism of Electron Beam Induced Oxide Layer Thickening on Iron-Iron Oxide Core-Shell Nanoparticles. J Phys Chem C 119: 8357-8363.

48. Dai S, Zhao J, Xie L, Cai Y, Wang N, et al. (2012) Electron-Beam-Induced Elastic-Plastic Transition in Si Nanowires. Nano Lett 12: 2379-2385.

49. Zhai Y, Han L, Wang P, Li G, Ren W, et al. (2011) Superparamagnetic Plasmonic Nanohybrids: Shape-Controlled Synthesis, TEM-Induced Structure Evolution, and Efficient Sunlight-Driven Inactivation of Bacteria. ACS Nano 5 : 8562-8570.

50. Tan SF, Bosman M, Nijhuis CA (2017) Molecular Coatings for Stabilizing Silver and Gold Nanocubes under Electron Beam Irradiation. Langmuir 33: 1189-1196.

51. Ramachandramoorthy R, Bernal R, Espinosa HD (2015) Pushing the Envelope of In Situ Transmission Electron Microscopy. ACS Nano 9: 4675-4685.

52. Zheng H, Meng YS, Zhu Y (2015) Frontiers of in situ electron microscopy. MRS Bulletin 40: 12-18.

53. Babitha KK, Priyanka KP, Sreedevi A, Ganesh S, Varghese T (2014) Effect of $8 \mathrm{MeV}$ electron beam irradiation on the structural and optical properties of $\mathrm{CeO} 2$ nanoparticles. Mater Charact 98: 222-227.

54. Hareesh K, Sanjeev G (2011) 8 MeV Electron Induced Changes in Structura and Thermal Properties of Lexan Polycarbonate. Mater Sci Appl 2: 1682-1687.

55. Rao PKS, Krishnan S, Pattabi M, Sanjeev G (2015) Electron irradiation induced modification of $\mathrm{Bi}_{2} \mathrm{Fe}_{4} \mathrm{O}_{9}$ nanoparticles. Int $\mathrm{J}$ Radiat Phys Chem 113: 36-40.

56. Raneesh B, Saha A, Kalarikkal N (2013) Effect of gamma radiation on the structural, dielectric and magnetoelectric properties of nanostructured hexagonal $\mathrm{YMnO}_{3}$. Int J Radiat Phys Chem 89: 28-32.

57. Sheena PA, Priyanka KP, Sabu NA, Ganesh S, Varghese T (2015) Effect of electron beam irradiation on the structure and optical properties of nickel oxide nanocubes. Bull Mater Sci 38: 825-830.

58. Wang W, Bai X, Guan X, Shen X, Yao Y, et al. (2017). In situ TEM observation of novel chemical evolution of $\mathrm{MnBr} 2$ catalyzed by $\mathrm{Cu}$ under electron beam irradiation. Chem Phys Lett 686: 44-48.

59. Yuk JM, Park J, Ercius P, Kim K, Hellebusch DJ, et al. (2012) High-Resolution EM of Colloidal Nanocrystal Growth Using Graphene Liquid Cells. Sci 336: 61-64.

60. Liao HG, Zherebetskyy D, Xin H, Czarnik C, Ercius P, et al. (2014) Facet development during platinum nanocube growth. Sci 345: 916-919.

61. McDowell MT, Lu Z, Koski KJ, Yu JH, Zheng G, et al. (2015) In Situ Observation of Divergent Phase Transformations in Individual Sulfide Nanocrystals. Nano Lett 15: 1264-1271.

62. Lin YC, Dumcenco DO, Huang YS, Suenaga K (2014) Atomic mechanism of the semiconducting-to-metallic phase transition in single-layered $\mathrm{MoS}_{2}$. Nat Nanotechnol 9: 391-396

63. Baldi A, Narayan TC, Koh AL, Dionne JA (2014) In situ detection of hydrogeninduced phase transitions in individual palladium nanocrystals. Nat Mater 13 1143-1148.

64. Yen MY, Chiu CW, Chen FR, Kai JJ, Lee CY, et al. (2004) Convergent Electron Beam Induced Growth of Copper Nanostructures: Evidence of the Importance of a Soft Template. LANGD5 20: 279-281.

65. Gonzalez MIG, Gemming T, Mendes R, Bachmatiuk A, Bezugly V, et al (2016) In-situ Quasi-Instantaneous e-beam Driven Catalyst-Free Formation Of Crystalline Aluminum Borate Nanowires. Sci Rep p: 22524

66. Jesse S, Borisevich AY, Fowlkes JD, Lupini AR, Rack PD, et al. (2016) Directing Matter: Towards Atomic Scale 3D Nanofabrication. ACS Nano 1: 5600-5618. 
Citation: Andrés J, Longo E, Gouveia AF, Costa JPC, Gracia L, et al. (2018) situ Formation of Metal Nanoparticles through Electron Beam Irradiation: Modeling Real Materials from First-Principles Calculations. J Material Sci Eng 7: 461. doi: 10.4172/2169-0022.1000461

67. Mansourian A, Paknejad SA, Zayats AV, Mannan SH (2016) Stereoscopic Nanoscale-Precision Growth of Free-Standing Silver Nanorods by Electron Beam Irradiation. J Phys Chem 120: 20310-20314.

68. Yang F, Zhao Q, Xu C, Zou Y, Dong H, et al. (2016) Unveiling the Switching Riddle of Silver Tetracyanoquinodimethane Towards Novel Planar SingleCrystalline Electrochemical Metallization Memories. Adv Mater 28: 7094-7100.

69. Sone H, Tamura T, Miyazaki K, Hosaka S (2006) Nano-dots formation on silver sulphide surface using electron beam irradiation. Microelectron Eng 83: 14871490.

70. Lee M, O’Hayre R, Prinz FB, Gür TM (2004) Electrochemical nanopatterning of $\mathrm{Ag}$ on solid-state ionic conductor RbAg4I5 using atomic force microscopy. Appl Phys Lett 85: 3552-3554.

71. Longo E, Cavalcante LS, Volanti DP, Gouveia AF, Longo VM, et al. (2013) Direct in situ observation of the electron-driven synthesis of $\mathrm{Ag}$ filaments on $\alpha-\mathrm{Ag}_{2} \mathrm{WO}_{4}$ crystals. Sci Rep 3 p: 1676

72. Ohno T, Hasegawa T, Tsuruoka T, Terabe K, Gimzewski JK, et al. (2011) Short-term plasticity and long-term potentiation mimicked in single inorganic synapses. Nat Mater 10: 591-595

73. Liang XF, Chen Y, Chen L, Yin J, Liu ZG (2007) Electric switching and memory devices made from RbAg4I ${ }_{5}$ films. Appl Phys Lett 90 p: 22508.

74. Hasegawa T, Terabe K, Tsuruoka T, Aono M (2012) Atomic Switch: Atom/ Ion Movement Controlled Devices for Beyond Von-Neumann Computers. Adv Mater 24: 252-267.

75. Kim SH, Choi YS, Kang K, Yang SI (2007) Controlled growth of bismuth nanoparticles by electron beam irradiation in TEM. J Alloys Compd 427: 330-332.

76. Sepulveda GS, Elizondo VN, Ferrer D, Torres CA, Gao X, et al. (2007) In situ formation of bismuth nanoparticles through electron-beam irradiation in a transmission electron microscope. Nanotechnol 18: 335-604.

77. Chang X, Wang S, Qi Q, Gondal MA, Rashid SG, et al. (2015) Insights into the growth of bismuth nanoparticles on 2D structured BiOCl photocatalysts: an in situ TEM investigation. Dalton Trans 44: 15888-15896.

78. Sichert JA, Tong Y, Mutz N, Vollmer M, Fischer S, et al. (2015) Quantum Size Effect in Organometal Halide Perovskite Nanoplatelets. Nano Lett 15: 65216527.

79. Zhu F, Men L, Guo Y, Zhu Q, Bhattacharjee U, et al. (2015) Shape Evolution and Single Particle Luminescence of Organometal Halide Perovskite Nanocrystals. ACS Nano 9: 2948-2959.

80. Dou L, Wong AB, Yu Y, Lai M, Kornienko N, et al. (2015) Atomically thin twodimensional organic-inorganic hybrid perovskites. Sci 349: 1518-1521.

81. Dang Z, Shamsi J, Palazon F, Imran M, Akkerman QA, et al. (2017) In Situ Transmission Electron Microscopy Study of Electron Beam-Induced Transformations in Colloidal Cesium Lead Halide Perovskite Nanocrystals. ACS Nano 11: 2124-2132.

82. Yu Y, Zhang D, Kisielowski C, Dou L, Kornienko N, et al. (2016) Atomic Resolution Imaging of Halide Perovskites. Nano Lett 16: 7530-7535.

83. Tong Y, Bladt E, Aygüler MF, Manzi A, Milowska KZ, et al. (2016) Highly Luminescent Cesium Lead Halide Perovskite Nanocrystals with Tunable Composition and Thickness by Ultrasonication. Angew Chem Int Ed 55: $13887-$ 13892.

84. Imran M, Di Stasio F, Dang Z, Canale C, Khan AH, et al. (2016) Colloidal Synthesis of Strongly Fluorescent $\mathrm{CsPbBr}_{3}$ Nanowires with Width Tunable down to the Quantum Confinement Regime. Chem Mater 28: 6450-6454.

85. Shamsi J, Dang Z, Bianchini P, Canale C, Di Stasio F, et al. (2016) Colloidal Synthesis of Quantum Confined Single Crystal $\mathrm{CsPbBr}_{3}$ Nanosheets with Lateral Size Control up to the Micrometer Range. J Am Chem Soc 138: 72407243.

86. Akkerman QA, Motti SG, Srimath KAR, Mosconi E, D'Innocenzo V, et al. (2016) Solution Synthesis Approach to Colloidal Cesium Lead Halide Perovskite Nanoplatelets with Monolayer-Level Thickness Control. J Am Chem Soc 138: 1010-1016.

87. Stanley HB, Banerjee D, Van Breemen L, Ciston J, Liebscher CH, et al. (2014) $X$-ray irradiation induced reduction and nanoclustering of lead in borosilicate glass. Cryst Eng Comm 16: 9331-9339.
88. Philippe B, Park BW, Lindblad R, Oscarsson J, Ahmadi S, et al. (2015) Chemical and Electronic Structure Characterization of Lead Halide Perovskites and Stability Behavior under Different Exposures-A Photoelectron Spectroscopy Investigation. Chem Mater 27: 1720-1731.

89. Evans JE, Jungjohann KL, Browning ND, Arslan I (2011) Controlled Growth of Nanoparticles from Solution with In Situ Liquid Transmission Electron Microscopy. Nano Lett 11: 2809-2813.

90. Zheng H, Smith RK, Jun YW, Kisielowski C, Dahmen U, et al. (2009) Observation of Single Colloidal Platinum Nanocrystal Growth Trajectories. Sc 324: 1309-1312.

91. Liao HG, Cui L, Whitelam S, Zheng $\mathrm{H}$ (2012) Real-Time Imaging of $\mathrm{Pt}_{3} \mathrm{Fe}$ Nanorod Growth in Solution. Sci 336: 1011-1014.

92. Woehl TJ, Evans JE, Arslan I, Ristenpart WD, Browning ND (2012) Direct In Situ Determination of the Mechanisms Controlling Nanoparticle Nucleation and Growth. ACS Nano 6: 8599-8610

93. Bogle KA, Dhole SD, Bhoraskar VN (2006) Silver nanoparticles: synthesis and size control by electron irradiation. Nanotechnol 17: 3204

94. Donev EU, Schardein G, Wright JC, Hastings JT (2011) Substrate effects on the electron-beam-induced deposition of platinum from a liquid precursor. Nanoscale 3: 2709-2717

95. Sutter E, Jungjohann K, Bliznakov S, Courty A, Maisonhaute E, et al. (2014) In situ liquid-cell electron microscopy of silver-palladium galvanic replacement reactions on silver nanoparticles. Nat Commun 5: 4946.

96. Belloni J (2006) Nucleation, growth and properties of nanoclusters studied by radiation chemistry: Application to catalysis. Catal Today 113: 141-156.

97. Pattabi M, Pattabi RM, Sanjeev G (2009) Studies on the growth and stability of silver nanoparticles synthesized by electron beam irradiation. J Mater Sci: Mater Electron 20: 1233-1238.

98. Belloni J, Mostafavi M, Remita H, Marignier JL, Marie OD (1998) Radiationinduced synthesis of mono- and multi-metallic clusters and nanocolloids. New J Chem 22: 1239-1255

99. Henglein A (1993) Physicochemical properties of small metal particles in solution: "microelectrode" reactions, chemisorption, composite metal particles and the atom-to-metal transition. J Phys Chem 97: 5457-5471.

100. Treguer M, De Cointet C, Remita H, Khatouri J, Mostafavi M, et al. (1998) Dose Rate Effects on Radiolytic Synthesis of Gold-Silver Bimetallic Clusters in Solution. J Phys Chem 102: 4310-4321.

101. Seong-Eun K, Young Hwan H, Byung cheol L, Jong Chan L (2010) One-pot fabrication of various silver nanostructures on substrates using electron beam irradiation. Nanotechnol 21: 075302.

102. Marignier JL, Belloni J, Delcourt MO, Chevalier JP (1985) Microaggregates of non-noble metals and bimetallic alloys prepared by radiation-induced reduction. Nat 317: 344-345.

103. Botman A, Mulders JJL, Hagen CW (2009) Creating pure nanostructures from electron-beam-induced deposition using purification techniques: a technology perspective. Nanotechnol 20: 372001.

104. Huth M, Porrati F, Schwalb C, Winhold M, Sachser R, et al. (2012) Focused electron beam induced deposition: A perspective. Beilstein J Nanotechnol 3 : 597-619.

105. Wnuk JD, Rosenberg SG, Gorham JM, Van Dorp WF, Hagen CW, et al. (2011) Electron beam deposition for nanofabrication: Insights from surface science. Surface Science 605: 257-266.

106. van Dorp WF, Hagen CW (2008) A critical literature review of focused electron beam induced deposition. Journal of Applied Physics 104: 081301.

107. Kim TW, Shin JW, Lee JY, Jung JH, Lee JW, et al. (2007) Electron-beaminduced formation of $\mathrm{Zn}$ nanocrystal islands in a SiO2 layer. Appl Phys Let 90: 051915.

108. Shim JH, Cho NH, Kim JG, Kim YJ (2009) Effect of Al addition on the crystallization of a-AlxSi1-x $(0.025 \leqslant x \leqslant 0.100)$ by electron-beam irradiation. J Non-Cryst Solids 355: 2339-2344.

109.Tseng AA, Kuan C, Chen CD, Ma KJ (2003) Electron beam lithography in nanoscale fabrication: recent development. IEEE Trans Electron Packag Manuf 26: 141-149. 
Citation: Andrés J, Longo E, Gouveia AF, Costa JPC, Gracia L, et al. (2018) situ Formation of Metal Nanoparticles through Electron Beam Irradiation: Modeling Real Materials from First-Principles Calculations. J Material Sci Eng 7: 461. doi: 10.4172/2169-0022.1000461

110. Altissimo M (2010) E-beam lithography for micro-nanofabrication. Biomicrofluidics 4: 026503

111. Furuya K (2008) Nanofabrication by advanced electron microscopy using intense and focused beam*. Sci Technol Adv Mater 9: 014110.

112. Ghatak J, Guan W Mobus G (2012) In situ TEM observation of lithium nanoparticle growth and morphological cycling. Nanoscale 4: 1754-1759.

113. Neng W, Sun LT, Hu XH, Zhu YY, Lin Z, et al. (2012) Charge Supported Growth and Superplasticity of Sodium Nanostructures. Cryst Growth Des 12 3899-3905.

114. Wang PI, Zhao YP, Wang GC, Lu TM (2004) Novel growth mechanism of single crystalline Cu nanorods by electron beam irradiation. Nanotechnol 15: 218.

115. Anderson PA, Edmondson MJ, Edwards PP, Gameson I, Meadows PJ, et al (2005) Production of Ultrafine Single-Crystal Copper Wires through Electron Beam Irradiation of Cu-containing Zeolite $\mathrm{X}$. Zeitschrift für anorganische und allgemeine Chemie 631: 443-447.

116. Padhi SK, Gottapu SN, Krishna MG (2016) Electron-beam irradiation induced transformation of $\mathrm{Cu} 2(\mathrm{OH}) 3 \mathrm{NO} 3$ nanoflakes into nanocrystalline $\mathrm{CuO}$. Nanoscale 8: 11194-11201.

117. Kim JU, Cha SH, Shin K, Jho JY, Lee JC (2005) Synthesis of Gold Nanoparticles from Gold(I)-Alkanethiolate Complexes with Supramolecular Structures through Electron Beam Irradiation in TEM. J Am Chem Soc 127: 9962-9963.

118. Golberg D, Mitome M, Yin LW, Bando Y (2005) In situ growth of Indium nanocrystals on $\mathrm{InP}$ nanorods mediated by electron beam of transmission electron microscope. Chem Phys Lett 416: 321-326.

119. Gnanavel T, Möbus G (2012) In-situ cobalt nanocrystal synthesis by intense electron beams in TEM. Chem Phys Lett 371: 012047.

120. Tamou Y, Tanaka Si (1999) Formation and coalescence of tungsten nanoparticles under electron beam irradiation. Nanostruct Mater 12: 123-126.

121. del Angel $P$, Rodriguez-Hernandez JH, Garcia-Borquez A, de la Fuente JAM (2013) Nucleation and growth of $\mathrm{NiO}$ nanoparticles and thin films by TEM electron irradiation. Catal Today 212: 194-200.

122. Yoji M, Osamu I, Akira O, Kenta O (2002) Preparation of Long Silver Nanowires from Silver Matrix by Electron Beam Irradiation. Chem Lett 31: 928-929.

123. Li K, Zhang FS (2010) A novel approach for preparing silver nanoparticles under electron beam irradiation. J Nanopart Res 12: 1423-1428.

124. Yuan ZY, Zhou W, Parvulescu V, Su BL (2003) Electron beam irradiation effect on nanostructured molecular sieve catalysts. J Electron Spectrosc Relat Phenom 129: 189-194.

125. Edmondson MJ, Zhou W, Sieber SA, Jones IP, Gameson I, et al. (2001) Electron-Beam Induced Growth of Bare Silver Nanowires from Zeolite Crystallites. Adv Mater 13: 1608-1611.

126. Makita Y, Ikai O, Hosokawa J, Ooi K, Okuyama S, et al. (2003) Synthesis of Long Silver Nanowires by Electron Beam Irradiation on Ag-exchanged Material. J Ion Exch 14: 409-412.

127. Umalas M, Vlassov S, Polyakov B, Dorogin LM, Saar R, et al. (2015) Electron beam induced growth of silver nanowhiskers. J Cryst Growth 410: 63-68.

128. Shi G, Bao S, Lai W, Rao Z, Zhang X, et al. (2013) Electron beam induced growth of silver nanoparticles. Scanning 35: 69-74.

129. Roca RA, Lemos PS, Andrés J, Longo E (2016) Formation of Ag nanoparticles on metastable $\beta$-Ag2WO4 microcrystals induced by electron irradiation. Chem Phys Lett 644: 68-72.

130.De Santana YV, Gomes JEC, Matos L, Cruvinel GH, Perrin A, et al. (2014) Silver molybdate and silver tungstate nanocomposites with enhanced photoluminescence. Nanomater Nanotechnol 4: 22.

131. Fabbro MT, Saliby C, Rios LR, La Porta FA, Gracia L, et al. (2015) Identifying and rationalizing the morphological, structural, and optical properties of beta$\mathrm{Ag} 2 \mathrm{MoO} 4$ microcrystals, and the formation process of $\mathrm{Ag}$ nanoparticles on their surfaces: combining experimental data and first-principles calculations. Sci Technol Adv Mater 16.

132. de Oliveira RC, Assis M, Teixeira MM, da Silva MDP, Li MS, et al. (2016) An
Experimental and Computational Study of $\beta$-AgVO3: Optical Properties and Formation of Ag Nanoparticles. J Phys Chem C 120: 12254-12264.

133. Botelho G, Sczancoski JC, Andres J, Gracia L, Longo E (2015) Experimenta and Theoretical Study on the Structure, Optical Properties, and Growth of Metallic Silver Nanostructures in Ag3PO4. J Phys Chem C 119: 6293-6306.

134. Fabbro MT, Gracia L, Silva GS, Santos LPS, Andrés J, et al. (2016) Understanding the formation and growth of $\mathrm{Ag}$ nanoparticles on silver chromate induced by electron irradiation in electron microscope: A combined experimental and theoretical study. J Solid State Chem 239: 220-227.

135. Pereira WdS, Andrés J, Gracia L, San-Miguel MA, Da Silva EZ, et al. (2015) Elucidating the real-time Ag nanoparticle growth on a-Ag2WO4 during electron beam irradiation: experimental evidence and theoretical insights. Phys Chem Chem Phys 17: 5352-5359.

136. Longo E, Volanti DP, Longo VM, Gracia L, Nogueira IC, et al. (2014) Toward an Understanding of the Growth of Ag Filaments on a-Ag2WO4 and Their Photoluminescent Properties: A Combined Experimental and Theoretica Study. J Phys Chem C 118: 1229-1239.

137. Andrés J, Gracia L, Gonzalez-Navarrete P, Longo VM, Avansi W, et al. (2014) Structural and electronic analysis of the atomic scale nucleation of $\mathrm{Ag}$ on a-Ag2WO4 induced by electron irradiation. Sci Rep 4: 5391

138. Lin Z, Li J, Zheng Z, Yan J, Liu P, et al. (2015) Electronic Reconstruction of a-Ag2WO4 Nanorods for Visible-Light Photocatalysis. ACS Nano 9: 7256-7265.

139.Xu D, Cheng B, Zhang J, Wang W, Yu J, et al. (2015) Photocatalytic activity of Ag2MO4 (M = Cr, Mo, W) photocatalysts. J Mater Chem A 3: 20153-20166.

140. Thomas A, Janáky C, Samu GF, Huda MN, Sarker P, et al. (2015) Time- and Energy-Efficient Solution Combustion Synthesis of Binary Metal Tungstate Nanoparticles with Enhanced Photocatalytic Activity. Chem Sus Chem 8 : 1652-1663.

141. Sreedevi A, Priyanka KP, Babitha KK, Ganesh S, Vargheses T (2016) Influence of electron beam irradiation on structural and optical properties of a-Ag2WO4 nanoparticles. Micron 88: 1-6.

142. Paskevicius M, Hansen BRS, Jørgensen M, Richter B, Jensen TR (2017) Multifunctionality of silver closo-boranes. Nat Commun 8: 15136

143.Wang ZL (2000) Transmission Electron Microscopy of Shape-Controlled Nanocrystals and Their Assemblies. J Phys Chem B 104: 1153-1175.

144. Herley PJ, Jones W (1993) The generation of nanoscale metal particles from metal azides: A high resolution electron microscopic study. Zeitschrift für Physik D Atoms, Molecules and Clusters 26: 159-161.

145. Pyrz WD, Park S, Blom DA, Buttrey DJ, Vogt T (2010) High-Angle Annula Dark-Field Scanning Transmission Electron Microscopy Investigations of Bimetallic Nickel Bismuth Nanomaterials Created by Electron-Beam-Induced Fragmentation. J Phys Chem C 114: 2538-2543.

146. Pan ZW, Dai ZR, Wang ZL (2002) Lead oxide nanobelts and phase transformation induced by electron beam irradiation. Appl Phys Lett 80: 309-311.

147.Ru Q (1997) Nanocrystals synthesized by electron-beam induced fragmentation of vacancy-containing metals microspheres. Appl Phys Lett 71 1792-1794

148. Yu KY, Bufford D, Sun C, Liu Y, Wang H, et al. (2013) Removal of stackingfault tetrahedra by twin boundaries in nanotwinned metals. Nat Commun 4: 1377.

149. Hobbs IW (1979) Radiation Effects in Analysis of Inorganic Specimens. Introduction to Analytical Electron Microscopy, Plenum Press, New York.

150. Chelikowsky JR, Cohen ML (2015) Semiconductors: A pillar of pure and applied physics. J Appl Phys 117: 112812.

151.https://www.nature.com/articles/nmat4619.

152. Marzari N (2016) Materials modelling: The frontiers and the challenges. Nat Mater 15: 381-382.

153. Michaelides A (2016) Materials modelling in London (interview). Nat Mater 15: $371-372$.

154.Peters T (2013) Nonequilibrium Many-Body Theory of Quantum Systems: A Modern Introduction. Taylor and Francis p: 221

155. Nitzan A (2006) Chemical Dynamics in Condensed Phases: Relaxation Transfer and Reactions in Condensed Molecular Systems. Oxford University Press, UK. 
Citation: Andrés J, Longo E, Gouveia AF, Costa JPC, Gracia L, et al. (2019) situ Formation of Metal Nanoparticles through Electron Beam Irradiation: Modeling Real Materials from First-Principles Calculations. J Material Sci Eng 7: 461. doi: 10.4172/2169-0022.1000461

Page 13 of 13

156. Bader RFW (1990) Atoms in molecules : A quantum theory. Clarendon Press. Oxford, New York.

157. Matta CF, Boyd RJ (2007) An introduction to the quantum theory of atoms in molecules. The Quantum Theory of Atoms in Molecules. Wiley pp: 1-34.

158. Masse R, Tordjman I, Durif A (1976) Refinement of Crystal - Structure of Silver Monophosphate, Ag3PO4 - Existence of Hight-Temperature Form. Zeitschrift Fur Kristallographie 144: 76-81.

159. Yi Z, Withers RL, Liu Y (2011) A two-step approach towards solar-driven water splitting. Electrochem Commun 13: 28-30.

160. Yi Z, Ye J, Kikugawa N, Kako T, Ouyang S, et al. (2010) An orthophosphate semiconductor with photooxidation properties under visible-light irradiation. Nat Mater 9: 559-564.

161. Bi Y, Hu H, Ouyang S, Lu G, Cao J, et al. (2012) Photocatalytic and photoelectric properties of cubic Ag3PO4 sub-microcrystals with sharp corners and edges. Chem Commun 48: 3748-3750.

162. Bi Y, Ouyang S, Umezawa N, Cao J, Ye J (2011) Facet Effect of SingleCrystalline Ag3PO4 Sub-microcrystals on Photocatalytic Properties. J Am Chem Soc 133: 6490-6492.

163. Wang W, Cheng B, Yu J, Liu G, Fan W (2012) Visible-Light Photocatalytic Activity and Deactivation Mechanism of Ag3PO4 Spherical Particles. ChemAsian J 7: 1902-1908.

164.Kumar S, Surendar T, Shanker V (2014) Template-free and eco-friendly synthesis of hierarchical Ag3PO4 microcrystals with sharp corners and edges for enhanced photocatalytic activity under visible light. Mater Lett 123: 172-175.
165. Kresse G, Furthmuller J (1996) Efficiency of ab-initio total energy calculations for metals and semiconductors using a plane-wave basis set. Comput Mater Sci 6: $15-50$.

166. Kresse G, Hafner J (1994) Ab initio molecular-dynamics simulation of the liquid-metal-amorphous-semiconductor transition in germanium. Phys Rev B 49: 14251-14269.

167. Heyd J, Scuseria GE, Ernzerhof M (2003) Hybrid functionals based on a screened Coulomb potential. J Chem Phys 118: 8207-8215.

168. Krukau AV, Vydrov OA, Izmaylov AF, Scuseria GE (2006) Influence of the exchange screening parameter on the performance of screened hybrid functionals. J Chem Phys 125: 224106.

169. Reunchan P, Umezawa N (2013) Native defects and hydrogen impurities in Ag3PO4. Phys Rev B 87: 245205.

170. Kahk JM, Sheridan DL, Kehoe AB, Scanlon DO, Morgan BJ, et al. (2014) The electronic structure of silver orthophosphate: experiment and theory. J Mater Chem A 2: 6092-6099.

171.Popelier PLA (2000) Atoms in Molecules: An Introduction, Prentice Hall: Harlow, England.

172. Matta CF, Boyd RJ (2007) The Quantum Theory of Atoms in Molecules-From Solid State to DNA and Drug Design.Wiley, Weinheim.

173.Longo VM, De Foggi CC, Ferrer MM, Gouveia AF, André RS, et al. (2014) Potentiated Electron Transference in a-Ag2WO4 Microcrystals with $\mathrm{Ag}$ Nanofilaments as Microbial Agent. J Phys Chem A 118: 5769-5778. 